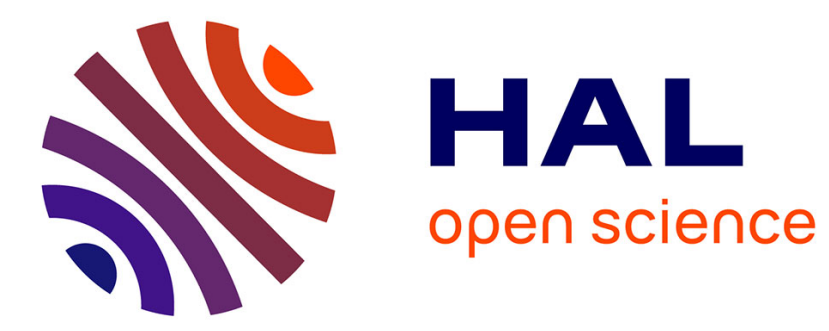

\title{
Radiation Induced Conductivity Of Space Used Polymers Under High Energy Electron Irradiation
}

\author{
T. Paulmier, B. Dirassen, M. Arnaout, D. Payan, N. Balcon
}

\section{To cite this version:}

T. Paulmier, B. Dirassen, M. Arnaout, D. Payan, N. Balcon. Radiation Induced Conductivity Of Space Used Polymers Under High Energy Electron Irradiation. Spacecraft Charging Technology Conference 2014 (13th SCTC), Jun 2014, PASADENA, United States. hal-01081923

\section{HAL Id: hal-01081923 \\ https://hal.science/hal-01081923}

Submitted on 12 Nov 2014

HAL is a multi-disciplinary open access archive for the deposit and dissemination of scientific research documents, whether they are published or not. The documents may come from teaching and research institutions in France or abroad, or from public or private research centers.
L'archive ouverte pluridisciplinaire HAL, est destinée au dépôt et à la diffusion de documents scientifiques de niveau recherche, publiés ou non, émanant des établissements d'enseignement et de recherche français ou étrangers, des laboratoires publics ou privés. 


\title{
Radiation Induced Conductivity Of Space Used Polymers Under High Energy Electron Irradiation
}

\author{
Thierry Paulmier, Bernard Dirassen, Mohamad Arnaout, Denis Payan, Nicolas Balcon
}

\begin{abstract}
Polymers are widely used on spacecraft for different specific functions : thermal and electrical insulation, mechanical support, adhesion... These polymers are highly sensitive to radiation met in space. Their electric properties is especially significantly altered leading to very specific behaviour in term of charge transport and discharge processes. Different dedicated facilities have been developed at ONERA, with CNES support, for the characterisation of space used materials in representative conditions. Thanks to the use of these different facilities, it has indeed been demonstrated that radiation induced conductivity of space polymers strongly affects the charging surface potential and depends on several parameters (radiation dose rate, total radiation dose, temperature and on the induced electric field) through complex physical mechanisms that are described in this paper. The sensitivity of polymers on these different parameters strongly depends upon polymer trap distribution and molecular configuration. Experimental as well as numerical results shall be presented in this paper, coupled with the different experimental techniques developed and applied in this work.
\end{abstract}

Keywords- Spacecraft Charging, Polymers, Radiation Induced Conductivity, Ionisation Effect, Charge Transport

\section{INTRODUCTION}

Dielectric materials used in space on satellite structure may have to cope with strong levels of charging under electron irradiation in space environment. This could lead to potential hazardous discharges and electric arcs and consequent anomalies on the satellite, such as electromagnetic disturbances or, in worst case, the destruction of some on-board systems. It is therefore of high importance to test and qualify space dielectric materials under representative charging conditions and to assess thoroughly their electric properties for realistic numerical predictions of charging levels that may be encountered on the satellite systems and sub-systems.

Polymers are widely used on spacecraft for thermal, optical and electrical application. Extensive experimental and numerical studies performed at ONERA allowed the identification and characterization of different physical mechanisms steering charging and relaxation kinetics on these materials. The charging behaviour of polymers strongly depends upon electron energy spectrum and fluxes and is directly dependent on ionisation processes induced by the high electron energy irradiation. Their electric conductivity is enhanced by radiation: we speak about radiation induced conductivity (RIC). This process has been thoroughly studied and described in some polymers (Teflon FEP for instance) : it has then been established, from former theories developed by Fowler [1] and Rose [2] and then amended by Gross [3] and

T. Paulmier and B. Dirassen are with ONERA, The French Aerospace Lab, Toulouse F-31055, France (e-mail: Thierry.Paulmier@onera.fr)

M. Arnaout is with Lebanese International University, Mazraa, Beirut 146404, Lebanon

D. Payan and N. Balcon are with CNES, The French Space Agency, 31401Toulouse Cedex 9, France
Tyutnev [4], for the description of interaction of polymers with high energy electrons, that RIC is basically steered by generation of electron-hole pairs through ionisation and by the electronic structure of the irradiated material (trap energy distribution and density). Several physical effects on RIC and charge transport in polymers are however not taken into account, such as induced detrapping or recombination, molecular mobility, polarisation processes and the overall effect of electric field on charge carrier dissociation and charge mobility.

RIC of different space used polymers has been investigated in this study at ONERA in the dedicated experimental facility SIRENE. For most of polymers, such as fluorine based polymers, polyimide or PEEK (Polyetheretherketone), it has been demonstrated that steady state for RIC is not yet observed after several hours irradiation. This process is described in this presentation, in which we explain the strong discrepancies observed on various polymers, in regard of charge carrier generation, detrapping, recombination and diffusion effect. The influence of structure, cristallinity and molecular mobility was of great importance to understand charge transport in these different polymers and especially the evolution of radiation induced conductivity. Basic and complex physics models, coupled with numerical tools for extraction of model parameters from experimental data, have been developed to understand and analyse the observed experimental features and for good prediction of charging behaviour and RIC evolution of these polymers under space conditions.

Numerical tools have been developed at ONERA to account for these physical mechanisms and validation has been performed through dedicated in-situ measurement techniques (Kelvin Probe method, Non-contact Pulsed Electroacoustic method (PEA), thermo-stimulated potential relaxation (TSPR)). We shall especially describe in this paper the experimental and numerical results coming out from surface potential measurements.

\section{EXPERIMENTAL SET-UP AND PROTOCOLS}

\section{A. Experimental facilities}

The experiments have been performed in the unique irradiation test facilities (SIRENE), funded by CNES and installed at ONERA (Toulouse, France) which allows charge characterization under GEO-like electron irradiation spectrum. Fig. 1 shows the electron beam spectral characteristics of the SIRENE facility with an energy spectrum $(\mathrm{Kp}>5)$ approaching that of the geostationary charging environment. 
(135)

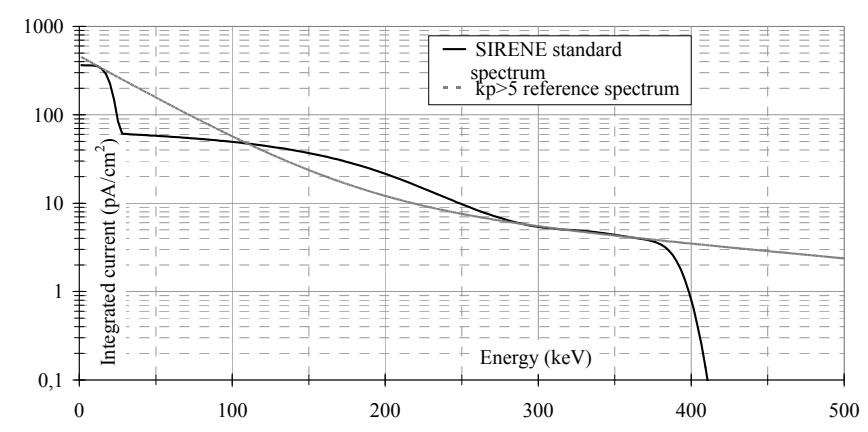

Fig. 1. SIRENE standard spectrum and reference $\mathrm{KP}>5$ spectrum [5]

SIRENE electron spectrum $([20 \mathrm{keV}, 250 \mathrm{pA} / \mathrm{cm} 2]+[0-$ $400 \mathrm{keV}, 50 \mathrm{pA} / \mathrm{cm} 2])$ experimental simulation is achieved with the use of two monoenergetic electron beams. In order to get a spacelike electron beam, the $400 \mathrm{keV}$ electron beam, passing through complex diffusion foils, is dispersed in energy from 0 to $400 \mathrm{keV}$. The nominal fluxes used for the $20 \mathrm{keV}$ monoenergetic beam and the distributed $400 \mathrm{keV}$ one are respectively equal $250 \mathrm{pA} / \mathrm{cm}^{2}$ and $50 \mathrm{pA} / \mathrm{cm}^{2}$ but can be raised respectively up to $1 \mathrm{nA} / \mathrm{cm}^{2}$ and $200 \mathrm{pA} / \mathrm{cm}^{2}$. A pumping system allows experiments at vacuum of around $10^{-6} \mathrm{mbar}$. The temperature of the sample holder can be controlled in the range of $-180^{\circ} \mathrm{C}$ to $250^{\circ} \mathrm{C}$ allowing to reproduce the temperature variation of materials on flight. The evolution of charging potential, during and after beam cut-off are monitored using a non-contact electrostatic probe (Kelvin probe TREK 3455ET) coupled with an electrostatic voltmeter (TREK 341B).

An other facility called SPIDER (Storage of Post Irradiated Dielectrics for Electron Relaxation) enables storing irradiated materials under vacuum (up to $10^{-6} \mathrm{hPa}$ ) for a long period of time (up to 1 or 2 years) to study relaxation physical processes of these materials through various in-situ, controlled and automatic measurements (surface potential with Kelvin probe, leakage and displacement currents, Non-contact Pulsed Electro-acoustic Method [PEA]). Fig. 2 presents a view of this SPIDER facility installed at ONERA (Toulouse).

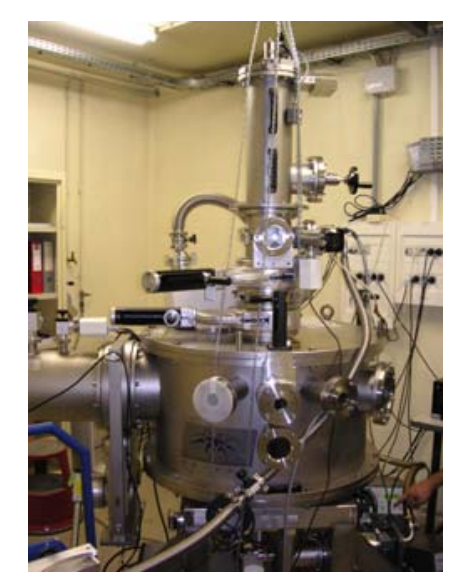

Fig. 2. View of the SPIDER facility
These different facilities allowed a thorough description of RIC dependence with applied parameters (radiation dose rate, total dose, temperature, electric field, ...). Recovery and ageing processes have also been analysed through dedicated experimental protocols allowing the optimisation of physics model used for charging prediction in space environment.

\section{B. Experimental protocols}

Dedicated method have been devised at ONERA for the evaluation of intrinsic and radiation induced conductivities. Characterization of space material conductivities is then usually performed in our studies using the surface potential decay method. For this method, bulk induced conductivity is assessed through the analysis of the surface potential relaxation after charging the sample with low energy electrons $(20 \mathrm{keV})$ up to a given surface potential [5]. During the electric voltage relaxation, a $400 \mathrm{keV}$ penetrating ionising electron beam (which does not contribute to material charging) is used to stimulate the potential decay through the activation of the radiation induced conductivity. To evaluate bulk conductivity of space materials, the material sample is modelled as a combination of a capacitance and resistance in parallel [6]. According to current conservation law, we can write:

$$
\mathrm{J}_{\mathrm{RIC}}=\mathrm{J}_{0}-\mathrm{J}_{\mathrm{ES}}-\mathrm{J}_{\mathrm{s}}-\mathrm{dq} / \mathrm{dt}
$$

where $\mathrm{J}_{\mathrm{RIC}}$ is the bulk conduction current, $\mathrm{J}_{0}$ the incident electron current, Js the surface leakage current density which depends upon incident energy $\mathrm{W}_{0}$ and current density $\mathrm{J}_{0}$ $\left(\mathrm{J}_{\mathrm{s}}=\beta\left[\mathrm{W}_{0}, \mathrm{~J}_{0}\right] . \mathrm{J}_{0}\right), \mathrm{dq} / \mathrm{dt}$ the temporal evolution of space charge displacement $(\mathrm{dq} / \mathrm{dt}=1 / \mathrm{S} . \mathrm{dQ} / \mathrm{dt}=\varepsilon / \mathrm{L} \cdot \mathrm{dV} / \mathrm{dt})$ and $\mathrm{J}_{\mathrm{ES}}$ the leakage current density resulting from electronic emission $\left(\mathrm{J}_{\mathrm{ES}}=\psi . \mathrm{J}_{0}\right)$

These equations lead to $\mathrm{Eq}(2)$ :

$$
\sigma_{\text {RIC }}(t)=1 / V \cdot\left[(1-\psi-\beta) . J_{0} \cdot L-\varepsilon \cdot d V / d t\right]
$$

where $\mathrm{V}$ the absolute surface potential, $\psi$ the total electron emission yield, $\beta$ the leakage surface current coefficient, $L$ the space charge distance to the ground and $\varepsilon$ the material permittivity.

From this experimental method, we can therefore assess the evolution of RIC as a function of radiation dose rate, radiation dose, electric field and temperature. To study the effect of electric field, the basic principle is to charge the sample with low energy electrons $(20 \mathrm{keV})$ up to a given surface potential (or given macroscopic electric field). Low energy irradiation is then stopped and potential relaxation is enhanced with the initiation of high energy $400 \mathrm{keV}$ electron irradiation that triggers radiation induced conductivity in the material bulk.

Different fluorine polymers (FEP, ETFE, PTFE), Kapton ${ }^{\circledR}$ and PEEK (not presented in this paper) have been tested as well under GEO-like electron irradiation (SIRENE spectrum) for a few hours. Radiation induced conductivity (RIC) is usually described in space community with the empirical law:

$$
\sigma_{\text {RIC }}(t)=k \cdot(d D / d t)^{\Delta}
$$


(135)

for which $\mathrm{k}$ and $\Delta$ are empirical parameters and $\mathrm{dD} / \mathrm{dt}$ is the radiation dose rate.

In this relation, RIC is supposed to be constant along the irradiation process. This paper demonstrates that the nonequilibrium profiles are never observed due to an evolution of RIC with radiation dose (and not only to radiation dose rate).

\section{EXPERIMENTAL RESULTS}

\section{A. Characterisation of RIC effect}

Fig. 3 presents the evolution of surface potential measured on Kapton $(127 \mu \mathrm{m}$ thick) irradiated by low energy $20 \mathrm{keV}$ electron beam or GEO-like electron spectrum. We can clearly notice that surface potential levels reached by the sample differs between both configurations: at $20 \mathrm{keV}$, Kapton ${ }^{\circledR}$ material bulk is not submitted to any electron irradiation, in opposition with geostationary like electron irradiation for which bulk radiation induced conductivity prevails. This leads to much higher surface potentials for low energy irradiation case. RIC initiation is especially conspicuous when looking at potential relaxation stimulated by $400 \mathrm{keV}$ electron radiation (Fig. 4). We can notice that RIC is conspiscuous even at very low electron flux, as seen in this Fig. 4 for which the $400 \mathrm{keV}$ radiation dose rate was as low as $0.1 \mathrm{pA} . \mathrm{cm}^{-2}$. This experiment reveals that RIC can steer at great level the charging potential met on internal spacecraft parts irradiated with high energy low fluxes.

It has been demonstrated as well that RIC is enhanced when increasing radiation dose rate and follows (during the first irradiation times) the conventional empirical law described in equation 3.

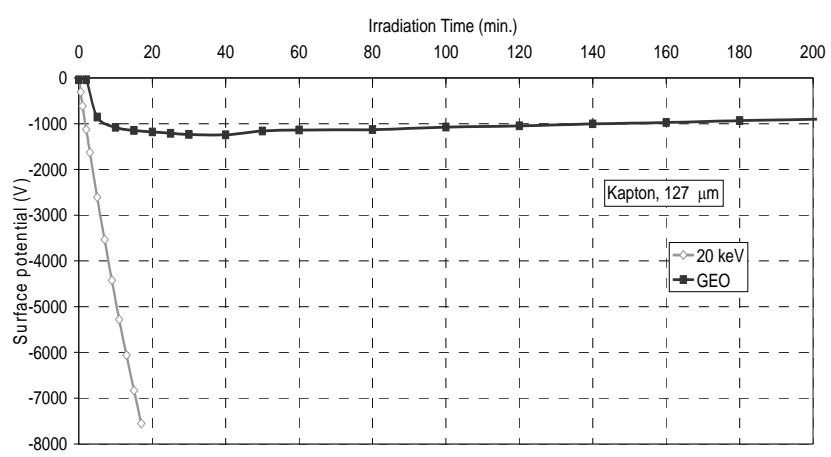

Fig. 3. Evolution of surface potential measured on Kapton ${ }^{\circledR}$ under monoenergetic $20 \mathrm{keV}$ electron irradiation or high energy geostationary (GEO) like electron irradiation

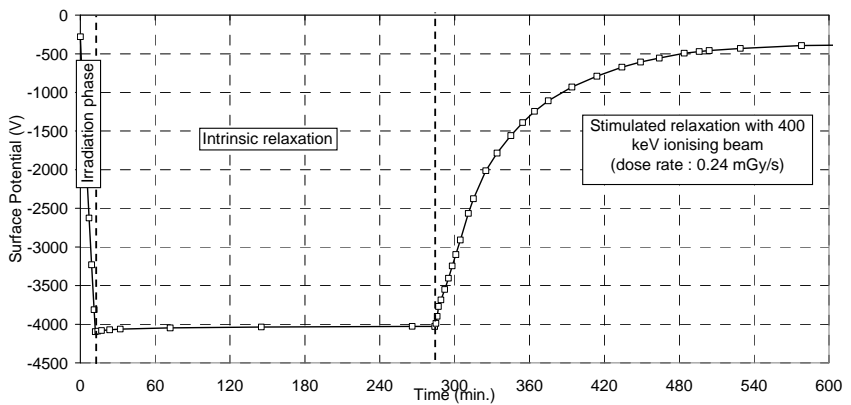

Fig. 4. Evolution of surface potential measured on Teflon ${ }^{\circledR}$ FEP at room temperature during three different phases : 1 . under mono-energetic $20 \mathrm{keV}$ electron irradiation, 2. during intrinsic relaxation, 3. during relaxation stimulated with $400 \mathrm{keV}$ electron beam (dose rate : $0.24 \mathrm{mGy} \cdot \mathrm{s}^{-1}$ )

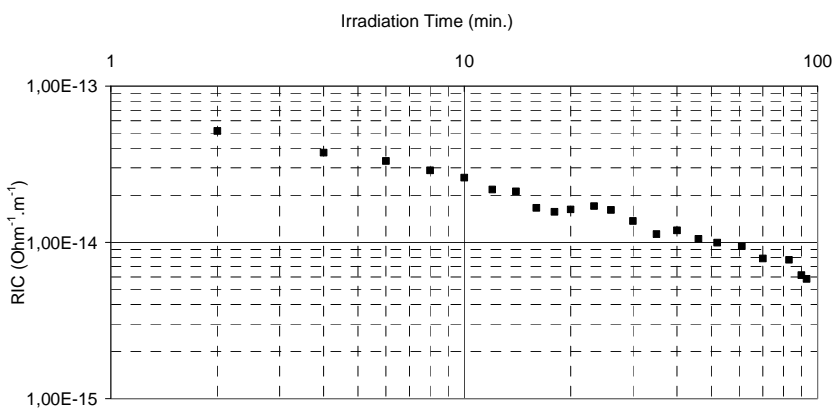

Fig. 5. Evolution of RIC on Kapton ${ }^{\circledR}$ (for a $400 \mathrm{keV}$ electron flux equal to 4 pA. $\mathrm{cm}^{-2}$ ) during the stimulated relaxation

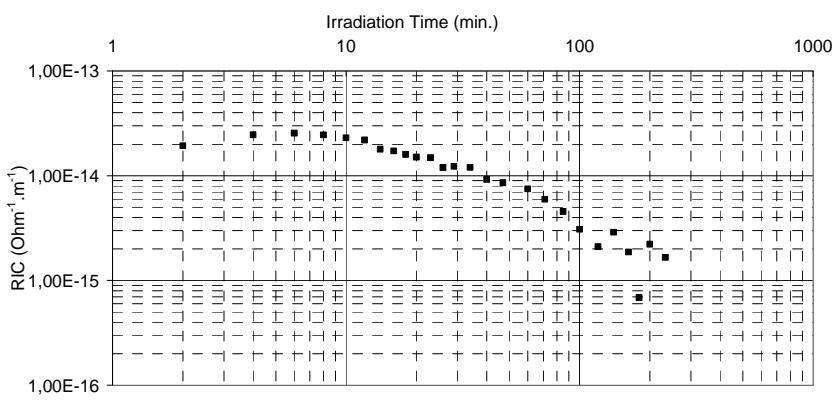

Fig. 6. Evolution of RIC on Teflon ${ }^{\circledR}$ (for a $400 \mathrm{keV}$ electron flux equal to 4 pA. $\mathrm{cm}^{-2}$ ) during the stimulated relaxation

From the relaxation kinetics stimulated with high energy electron beam (here $400 \mathrm{keV}$ electron beam), it is possible to draw the evolution of RIC as a function of relaxation time, as we can see in Fig. 5 and 6 for Kapton ${ }^{\circledR}$ and Teflon ${ }^{\circledR}$ FEP. For both materials, we can notice a steady decline of RIC along the irradiation. If this trend is not surprising on Teflon ${ }^{\circledR}$ (since we demonstrated in a previous study that RIC of Teflon steeply drops down with the increasing radiation dose [7]), it is however much more questionable for Kapton ${ }^{\circledR}$ since we demonstrated in previous studies that RIC steadily soars up with the increasing radiation dose [8]. Other mechanisms, than those taken into account by several authors [1-8], might therefore prevail during the stimulated relaxation. Applying these basic models for stimulated relaxation does not indeed induce any RIC decline but follows the same trend as those described above (RIC rises for Kapton ${ }^{\circledR}$, as we can see in 
(135)

Fig. 7). Among the different possible mechanisms, one can suspect that electric field effect on RIC could be of high importance : during stimulated relaxation, the surface potential indeed drops down, so does the electric field. The next step of our overall study on RIC of space used polymers was therefore to analyse possible effect of the electric field on this conductivity. Temperature may as well have an effect on RIC of space used polymers : this study was therefore focused on the assessment of this effect and the analysis of underlying physical mechanisms.

It is important to mention as well that RIC does not fade away instantaneously after the irradiation shut-down but can prevail for a long period of time: we speak about delayed radiation induced conductivity (DRIC). This process is conspicuous in Fig. 8 in which relaxation kinetics of surface potential for Teflon FEP is compared in two configurations: 1 . when the sample has been charged with low energy $20 \mathrm{keV}$ beam (no bulk radiation and therefore no bulk RIC), 2. when the sample has been irradiated with high energy electron spectrum (GEO like) for which it is submitted to RIC. We can clearly notice that relaxation kinetics is far higher in the second case due to the presence of DRIC initiated by the high energy electron radiation.

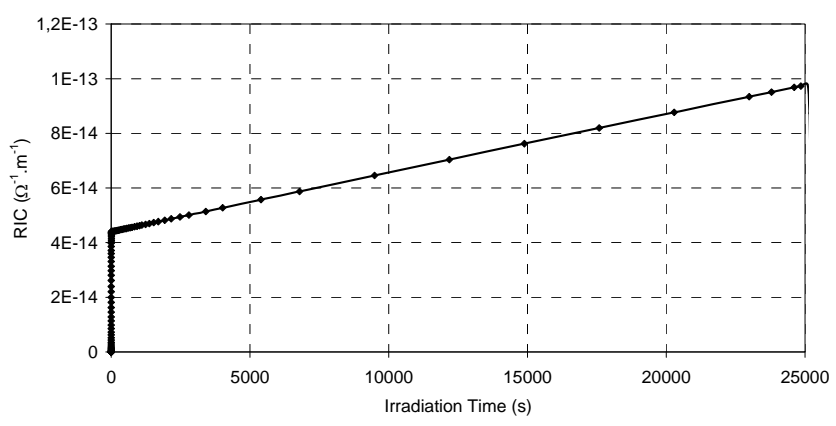

Fig. 7. Assessment of the evolution of RIC with basic first $0 \mathrm{D}$ model developed at ONERA for Kapton ${ }^{\circledR}$ irradiated under GEO like electron spectrum

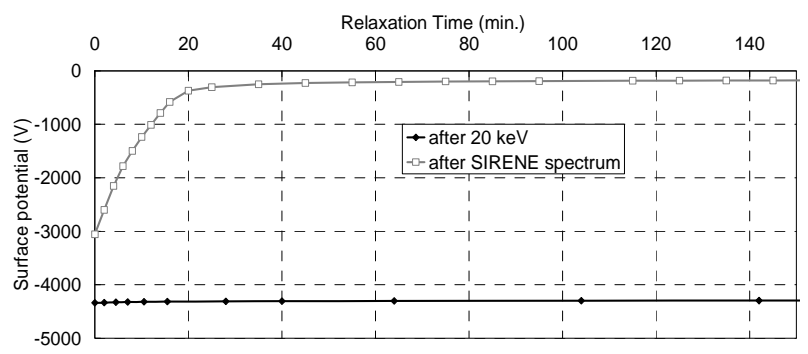

Fig. 8. Evolution of surface potential on $127 \mu \mathrm{m}$ thick Teflon FEP sample after $20 \mathrm{keV}$ electron irradiation or GEO like SIRENE spectrum

\section{B. Temperature effect on RIC}

As we shall demonstrate latter in this paper, Radiation Induced Conductivity is steered by different processes and physical parameters that can be highly sensitive to temperature change. Detrapping, generation rate, recombination and charge mobility are known to be temperature dependent. However, effect of temperature on RIC is usually not taken into account in conventional numerical codes used for spacecraft charging prediction. A comparison between Fig. 9 and Fig. 10 revealed that stimulated relaxation kinetics significantly fades away when temperature drops down. RIC has been assessed with surface potential decay method applied at different temperatures. Fig. 11 show indeed that RIC steeply soars up with temperature, with almost two decades increase between $150^{\circ} \mathrm{C}$ and room temperature for Kapton ${ }^{\circledR}$ and Teflon ${ }^{\circledR}$ FEP. analysis of these figures reveals that RIC of these materials can not be fitted with any Arrhenuis, Poole-Frenkel conventional laws or with the Onsager theoretical laws (described in next section to account for the effect of temperature and electric field on geminate recombination). This could be explained by the fact, as mentioned earlier, that RIC is steered by several temperature dependent physical mechanisms (detrapping, geminate recombination, carrier mobility, ...), leading to a complex thermal evolution for RIC. It is worth mentioning as well that temperature dependence of RIC is noticeable even for temperature below the glass transition temperature (which is higher than $360^{\circ} \mathrm{C}$ for Kapton $\mathrm{HN}$ [see technical data sheet provided by Dupont] and equal to around $80-150^{\circ} \mathrm{C}$ for Teflon FEP $[9,10])$.

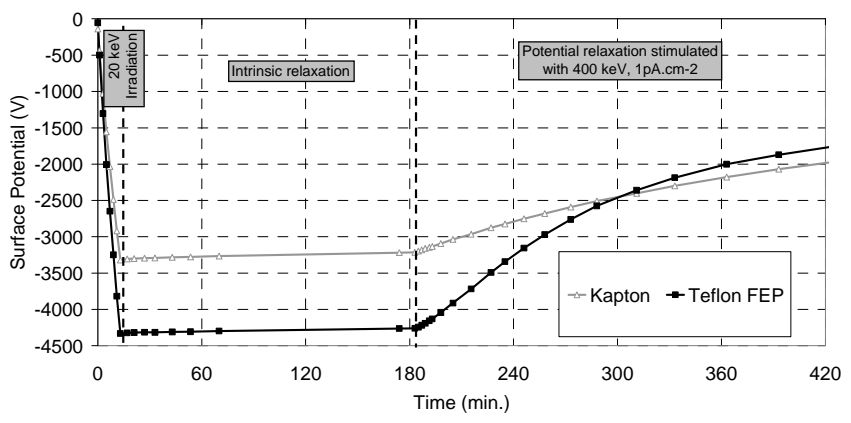

Fig. 9. Evolution of surface potential measured on Kapton $\left({ }^{\circledR}\right.$ and Teflon ${ }^{\circledR}$ at $=$ $30^{\circ} \mathrm{C}$ during three different phases : 1 . under mono-energetic $20 \mathrm{keV}$ electron irradiation, 2. during intrinsic relaxation, 3. during relaxation stimulated with $400 \mathrm{keV}$ electron beam (flux : $1 \mathrm{pA} \cdot \mathrm{cm}^{-2}$ )

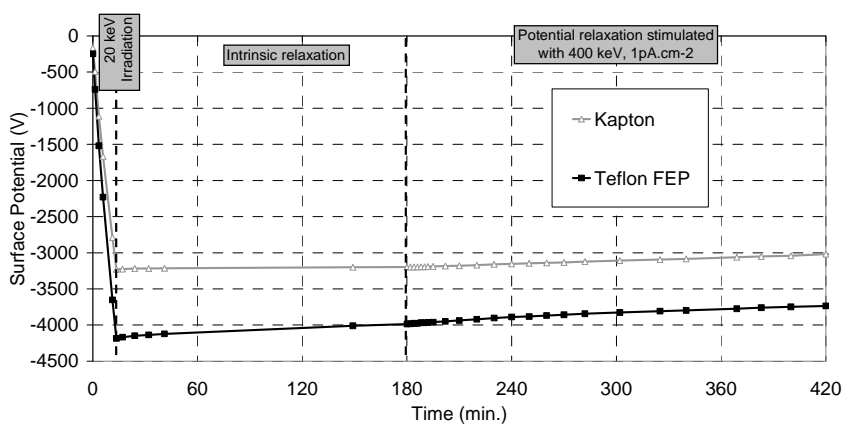

Fig. 10. Evolution of surface potential measured on Kapton ${ }^{\circledR}$ and Teflon ${ }^{\circledR}$ at

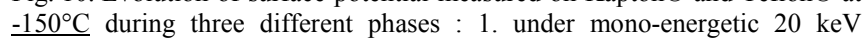
electron irradiation, 2. during intrinsic relaxation, 3. during relaxation stimulated with $400 \mathrm{keV}$ electron beam (flux : $1 \mathrm{pA} . \mathrm{cm}^{-2}$ ) 
(135)

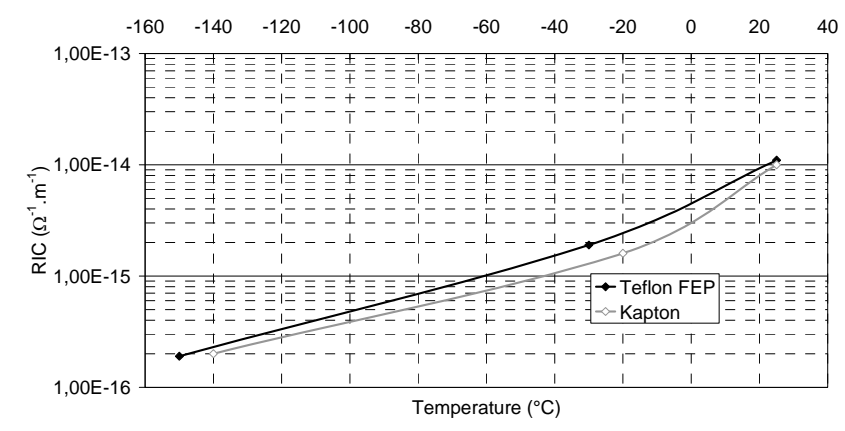

Fig. 11. Evolution of RIC for $127 \mu \mathrm{m}$ thick Kapton ${ }^{\circledR}$ and Teflon ${ }^{\circledR}$ (radiation dose rate : 2.5 mGy.s $\mathrm{s}^{-1}$, electric field : $3.10^{7} \mathrm{~V} \cdot \mathrm{m}^{-1}$ ) as a function of temperature

\section{Effect of electric field on RIC}

Physical processes steering RIC could be as well dependent on the electric field induced by charge implantation during irradiation. It has been demonstrated especially that charge mobility is field dependent. Numerous authors assume that dependence of conductivity on electric field is steered by electric field induced detrapping : Poole-Frenkel or AdamecCalderwood laws are often applied to describe the effect of electric field on conductivity through mobility change. Experimental tests revealed that RIC can be steered as well by geminate recombination which is field dependent. As seen in Fig. 12, dependence of RIC on electric field has been demonstrated as well through surface potential decay method (materials have been charged up to different surface potential and relaxation was stimulated at the same electron flux for the different tests). We can clearly notice on this figure a quasilinear dependence of RIC with electric field. This experimental feature can not be fitted with Poole-Frenkel or AdamecCalderwood laws but with Onsager law describing dependence of geminate recombination with electric field. In this theory, it is demonstrated that generation rate of electron-hole pairs is well described at low electric field by the following equation $[11,12,13]$ :

$$
\mathrm{P}=\exp \left(-\mathrm{e}^{2} / \varepsilon \cdot \mathrm{k} \cdot T \cdot \mathrm{r}_{0}\right) \cdot\left(1+\mathrm{e}^{3} \cdot \mathrm{E} / 8 \cdot \pi \cdot \varepsilon \cdot \mathrm{k}^{2} \cdot \mathrm{T}^{2}\right)
$$

in which e is the electronic charge, $\varepsilon$ the dielectric constant, $\mathrm{k}$ the Boltzmann constant, $\mathrm{T}$ the absolute temperature, $\mathrm{E}$ the electric field and $r_{0}$ the initial separation distance of an electron-hole pair.

Linear dependence of radiation induced conductivity with electric field has already been brought into evidence by Barlett et al [12]. It has been established and demonstrated through various experiments that RIC for Kapton ${ }^{\circledR}$ is especially steered by free holes (electrons being quickly trapped). During the first radiation times and based on previous charge transport models [6], it is possible to state, through basic rough calculation, that the density of free holes is given by the following equation [3] :

$$
\mathrm{p}=\mathrm{g} \cdot \tau_{\mathrm{p}} \cdot\left[1-\exp \left(-\mathrm{t} / \tau_{\mathrm{p}}\right)\right]
$$

for which $p$ is the holes density, $g$ the effective generation rate, $\tau_{\mathrm{p}}$ the trapping characteristic time for holes and the irradiation time.
With no mobility for electrons we can also write RIC as follows:

$$
\mathrm{RIC}=\mathrm{p} \cdot \mu_{\mathrm{p}}
$$

At time $\mathrm{t}=0$, RIC can then be written with the relation:

$$
\mathrm{RIC}=\mathrm{g}(\mathrm{E}) \cdot \tau_{\mathrm{p}} \cdot \mu_{\mathrm{p}}
$$

We can then state that RIC is directly proportional to the effective generation rate during the first radiation times. The linear dependence of RIC at low electric field seems then directly linked to geminate recombination. The slope to intercept ratio derived from the experimental tests presented in Fig. 12 (meaning $4.10^{-22} / 3.10^{-15}$ ) : the experimental ratio is indeed equal to $1.310^{-7} \mathrm{~m} . \mathrm{V}^{-1}$ versus $3.10^{-7} \mathrm{~m} . \mathrm{V}^{-1}$ for the theroretical ratio given by equation (4). It is interesting to mention as well that photoconduction of Kapton® illuminated with UV-Visible light is highly dependent on the applied electric field (Fig. 13). The experiments have been performed at ONERA under vacuum through Kelvin probe measurements. The sample is first charged up in darkness with low energy electrons $(20 \mathrm{keV})$ up to a given surface potential. The surface potential is then controlled continuously by placing the Kelvin probe in front of the Kapton sample. Potential relaxation is first recorded in darkness. An optic fiber placed at few millimeters from the sample surface allows then simultaneous in-situ photon radiation and surface potential measurements under vacuum. Different electric field levels have been applied through $20 \mathrm{keV}$ irradiation to study the effect of electric field on photo-conduction. We can notice from Fig. 13 that the lope to intercept ratio is equal to $1.10^{-7} \mathrm{~m} . \mathrm{V}^{-1}$ and close to the RIC and theoretical values.

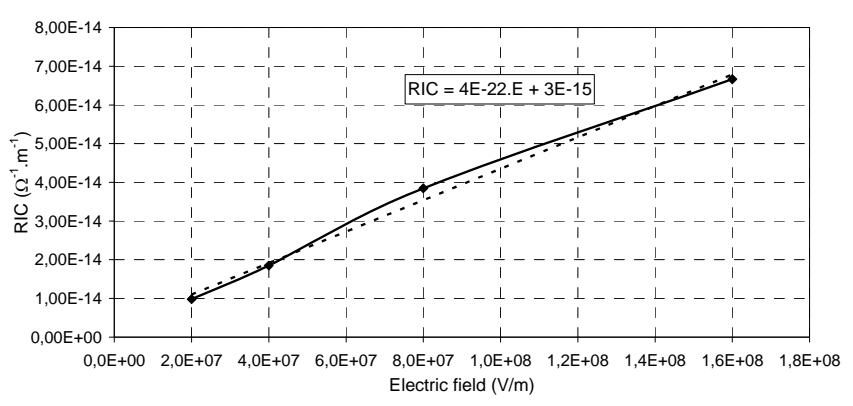

Fig. 12. Evolution of RIC for $127 \mu \mathrm{m}$ thick Kapton ${ }^{\circledR}$ (radiation dose rate : 2.5 mGy.s ${ }^{-1}$, Temperature : $20^{\circ} \mathrm{C}$ ) as a function of applied electric field

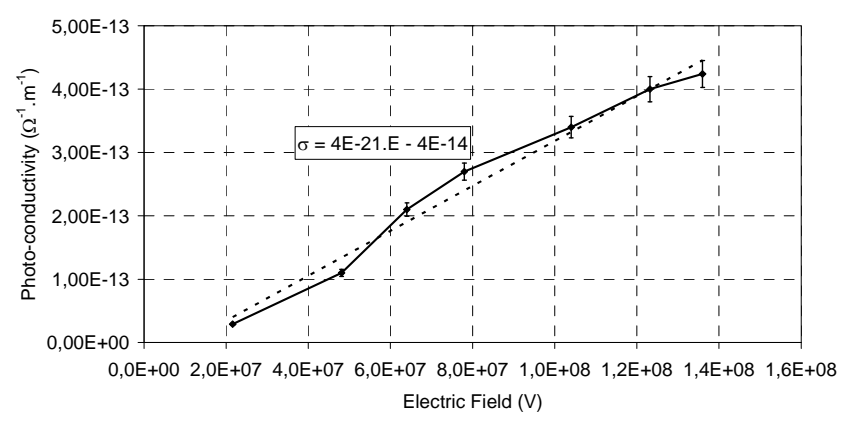

Fig. 13. Evolution of photo-conduction for $50 \mu \mathrm{m}$ thick Kapton ${ }^{\circledR}(\mathrm{UV} /$ visible light, Temperature : $20^{\circ} \mathrm{C}$ ) as a function of applied electric field 
We may think that, for longer irradiation times for which concentration of trapped charges is higher, electric field assisted detrapping process, known as Poole-Frenkel effect, might prevail and act on the evolution of RIC with radiation time. This electric field induced detrapping should as well steer delayed radiation induced conductivity. It has however been demonstrated [results shall be presented in an other future paper] through comparative studies between numerical and experimental results (for which electric field effect on RIC and DRIC could be discarded in the basic 0D two traps model [see next section]) that evolution of DRIC on Kapton was basically only and mainly ruled by electron-hole pair recombination and that detrapping kinetics does not strongly evolve within the applied electric field range.

\section{RIC of fluorine-base materials}

Three different fluorine based materials have been irradiated in SIRENE facility with the standard electron spectrum described in Fig. 1: Teflon ${ }^{\circledR}$ FEP, Ethylenetetrafluoroethylene (ETFE) and Polytetrafluoroethylene (PTFE). They have been submitted to two successive electron irradiations with the same standard SIRENE spectrum. The irradiation duration was 7 hours for the first step and 3 hours for the second step. The second irradiation step was initiated 15 hours after the end of the first step (15 hours relaxation between both steps).

Fig. 14 presents the evolution of the surface potential measured on each material during the first irradiation step. It is interesting to notice that each material presents its own specific charging behaviour. All three materials present a nonmonotonic behaviour: after the first charging step, they both tends to get more conductive (the surface absolute potential lowers). At a given radiation dose levels (or irradiation duration), charging kinetics is reduced to zero for ETFE and PTFE (a quasi-equilibrium state is then reached) or even reversed for Teflon ${ }^{\circledR}$ FEP. Their response in regard of the received radiation dose is moreover quite different from one material to the other. FEP and ETFE both present a nonmonotonic behaviour: after the first charging step, they both tends to get more conductive (the surface absolute potential lowers). ETFE tends however to keep up a lower electric conductivity than FEP in this experiment. PTFE present a very specific charging behaviour since it does not reveal any strong surface charging potential under GEO like electron irradiation. RIC for PTFE seems therefore be much higher than the other two fluorine materials whereas their chemical structures are very close. RIC has been assessed for the three fluorine materials applying the stimulated relaxation method. Results are presented in Fig. 15. For a radiation dose rate similar to the one applied in SIRENE spectrum, these results are in agreement with Fig. 14 with RIC for PTFE around 1 decade higher than FEP and ETFE RIC and RIC for ETFE being slightly lower than for FEP. An other interesting feature coming out from Fig. 15 is the difference of slope between FEP and PTFE inducing then higher RIC for PTFE at high dose rate and a reversed behaviour at very low dose rates (that can be met for internal charging issues). Despite similar chemical structure, cristallinity ratio and molecular chain conformation might be very different from one material to the other, which would lead to strong discrepancies in regard of charge carrier mobility and trap energy structure. One needs however mentioning that no strong differences are observed between the three fluorine materials in regard of their bulk intrinsic conductivity. RIC of these materials is mainly steered by holes transport which occurs through hopping process from one molecular branch to the other. This last process is steered then itself by molecular mobility. The nature of radicals generated by high energy radiation may also be drastically different between these fluorine materials : these radical species may play a significant role in charge transport, usually acting as additional traps for the charge carriers and can act as mobile transport site in regard of the molecular mobility of the material.

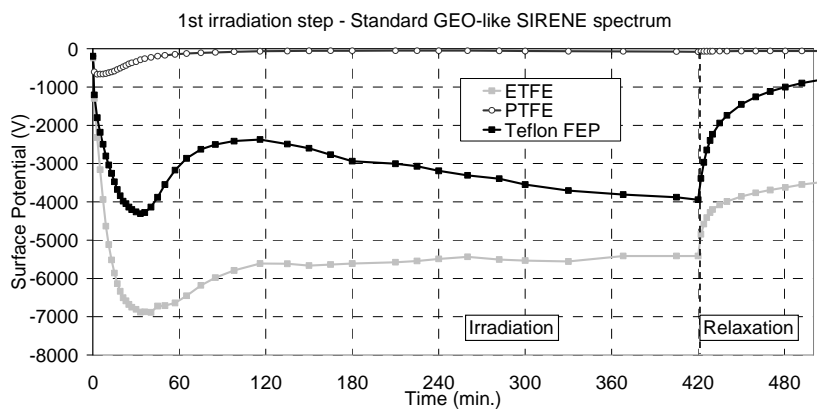

Fig. 14. Surface potentials measured during the first irradiation step on 100 $\mu \mathrm{m}$ thick fluorine based materials

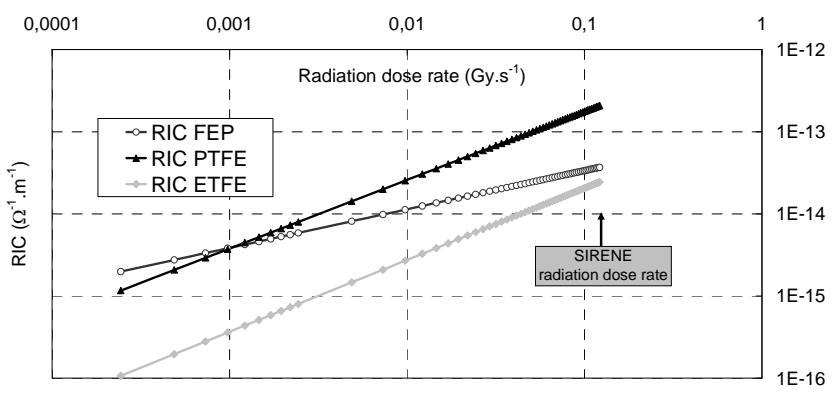

Fig. 15. Evolution of RIC as a function of radiation dose rate for FEP, PTFE and ETFE

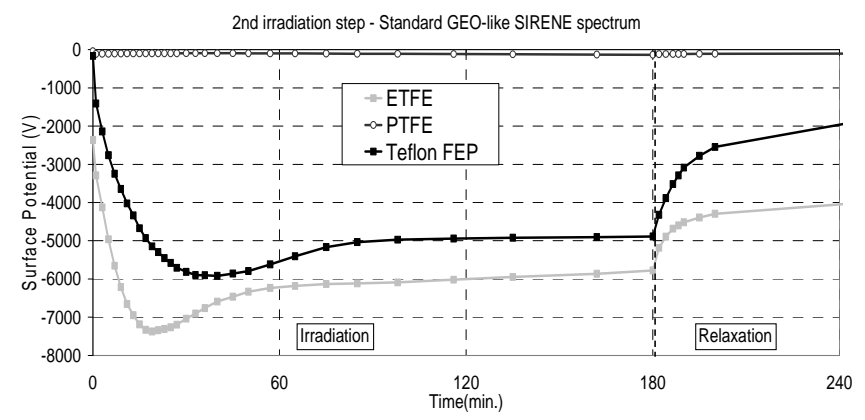

Fig. 16. Surface potentials measured during the second irradiation step on 100 $\mu \mathrm{m}$ thick fluorine based materials 
(135)

Fig. 16 presents the evolution of the surface potential measured on the different materials during the second irradiation step. The three tested materials behave quite differently due to radiation dose received previously during the first irradiation phase. FEP is significantly less conductive during the second phase: this process, as we describe in the next section, as been assigned to high density of trapped electrons which act as recombination centres for the generated free holes which then lowers the effective generation rate of this latter carriers. ETFE presents a slightly higher resistivity during the second step which could be attributed to the same recombination process. On the contrary to both previous materials, PTFE gets surprisingly more conductive in comparison with the first irradiation step. This effect can hardly be described by ageing effect which usually tends to induce crosslinking between the polymer chains and then reduce the charge carrier mobility. One might suggest either that radiation in PTFE induces chain scission or radical generation that shall enhance carrier mobility or that holes detrapping is more active for PTFE leading to a constant rise of free holes density in PTFE leading to a constant RIC enhancement along with radiation dose. The next section is a first physical and numerical approach to describe the evolution of surface potential observed above on different space used polymers.

\section{NUMERICAL ANALYSIS}

RIC and the experimental features are described through a basic 0D numerical model, initially developed by Rose [2] and Fowler [1] and adapted further on by different research teams [3-8]. In our study, this model has been amended for a better numerical prediction. It allows accounting for the experimental characteristics observed on the different tested polymers, through a competition between free carriers generation, trapping, detrapping and recombination processes.

Two levels of localized traps have been implemented in this model: one deep trap for which detrapping should be very low but should act as recombination centres if filled with electrons; a second trap corresponding to middle energy depth and for which detrapping is easier. Shallower traps are supposed to get in thermal equilibrium with the extended state. Mobility for free charges is therefore an average mobility taking into account this thermal equilibrium process. We assume as well that a free charge recombines with a localized charge with opposite sign. Based on the above assumptions and introducing charge detrapping process in the model, the equations describing the 0D RIC model are:

$$
\begin{aligned}
\mathrm{dn} / \mathrm{dt}=\mathrm{g}(\mathrm{E})-\alpha_{1} \mathrm{n}\left(\mathrm{p}_{\mathrm{t} 1}+\mathrm{p}_{\mathrm{t} 2}\right)-\mathrm{n} / \tau_{\mathrm{n} 1}-\mathrm{n} / \tau_{\mathrm{n} 2}+\mathrm{n}_{\mathrm{t} 1} / \tau_{\mathrm{nt} 1}+\mathrm{n}_{\mathrm{t} 2} / \tau_{\mathrm{nt} 2} \\
\mathrm{dp} / \mathrm{dt}=\mathrm{g}(\mathrm{E})-\alpha_{1} \mathrm{p}\left(\mathrm{n}_{\mathrm{t} 1}+\mathrm{n}_{\mathrm{t} 2}\right)-\mathrm{p} / \tau_{\mathrm{p} 1}-\mathrm{p} / \tau_{\mathrm{p} 2}+\mathrm{p}_{\mathrm{t} 1} / \tau_{\mathrm{pt} 1}+\mathrm{p}_{\mathrm{t} 2} / \tau_{\mathrm{pt} 2} \\
\mathrm{dn}_{\mathrm{t} 1} / \mathrm{dt}=\mathrm{n} / \tau_{\mathrm{n} 1}-\mathrm{n}_{\mathrm{t} 1} / \tau_{\mathrm{nt} 1}-\alpha_{2} \mathrm{pn}_{\mathrm{t} 1} \\
\mathrm{dn}_{\mathrm{t} 2} / \mathrm{dt}=\mathrm{n} / \tau_{\mathrm{n} 2}-\mathrm{n}_{\mathrm{t} 2} / \tau_{\mathrm{nt} 2}-\alpha_{2} \mathrm{pn}_{\mathrm{t} 2} \\
\mathrm{dp}_{\mathrm{t} 1} / \mathrm{dt}=\mathrm{p} / \tau_{\mathrm{p} 1}-\mathrm{p}_{\mathrm{t} 1} / \tau_{\mathrm{pt} 1}-\alpha_{1} \mathrm{np}_{\mathrm{t} 1} \\
\mathrm{dp}_{\mathrm{t} 2} / \mathrm{dt}=\mathrm{p} / \tau_{\mathrm{p} 2}-\mathrm{p}_{\mathrm{t} 2} / \tau_{\mathrm{pt} 2}-\alpha_{1} \mathrm{np}_{\mathrm{t} 2}
\end{aligned}
$$

for which $\mathrm{g}(\mathrm{E})$ is the electron / hole pairs generation rate which varies with the applied electric field, $\alpha_{1}$ and $\alpha_{2}$ are the recombination rates, $\mathrm{n}, \mathrm{n}_{\mathrm{t} 1}$ and $\mathrm{n}_{\mathrm{t} 2}$ are densities of free and trapped electrons, $p, p_{t 1}$ et $p_{t 2}$ are densities of free and trapped holes, $\tau_{\mathrm{n} 1}, \tau_{\mathrm{n} 2}, \tau_{\mathrm{p} 1}$ and $\tau_{\mathrm{p} 2}$ are trapping time for free electrons and holes, $\tau \mathrm{n}_{\mathrm{t} 1}, \tau \mathrm{n}_{\mathrm{t} 2}, \tau \mathrm{p}_{\mathrm{t} 1}$ and $\tau \mathrm{p}_{\mathrm{t} 2}$ detrapping time for trapped electrons and holes. We can then assess densities of free electrons and holes that are used in (11) for surface potential assessment:

$$
\frac{d V}{d t}=\frac{L j(1-\eta-\beta)-e\left(\mu_{n} n+\mu_{p} p\right) V}{\varepsilon}
$$

in which $\mathrm{L}$ is the sample thickness, $\mathrm{J}$ the incident flux of low energy implanted electrons $(20 \mathrm{keV}), \eta$ the secondary electron emission yield, $\beta$ is the surface leakage parameter, $\mathrm{V}$ the surface potential, e the elementary charge and $\varepsilon$ the material permittivity.

We present in this paper the numerical results for FEP and ETFE. We assume for these materials that electrons are quickly trapped, detrapping is very slow (due to high detrapping time) and free holes present high residence time in the valence band. The model parameters have been adjusted to fit qualitatively with the experimental results. Fig. 17 and 18 present the numerical results on FEP and ETFE for both irradiations steps. We can indeed notice that this model fits qualitatively quite well with the experimental features. The resistivity rise observed on both materials is assigned to the influence of trapped electrons that act as recombination centres for the generated free holes. For ETFE, free holes life time is higher than for FEP allowing reaching quasi-equilibrium between generation, trapping and recombination process. Shallow second trapping states allow especially a fairly high density of free charges during relaxation leading then to DRIC that can prevail for a longer and more realistic period of time than DRIC assessed with one trap level.

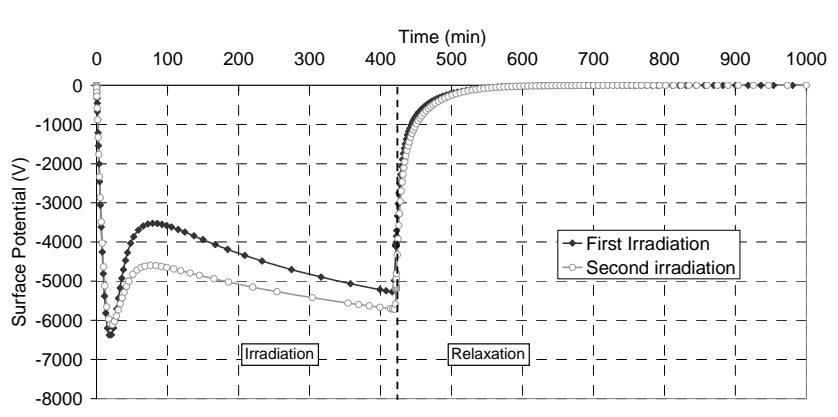

Fig. 17. Surface potential profiles assessed numerically for FEP under successive GEO irradiation 
(135)

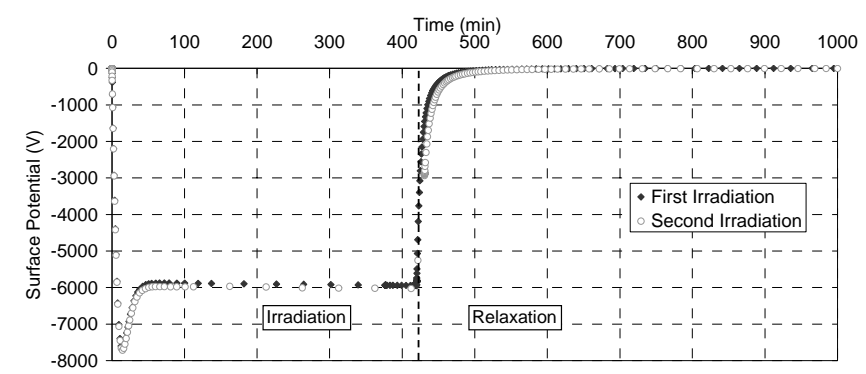

Fig. 18. Surface potential profiles assessed numerically for ETFE under successive GEO irradiation

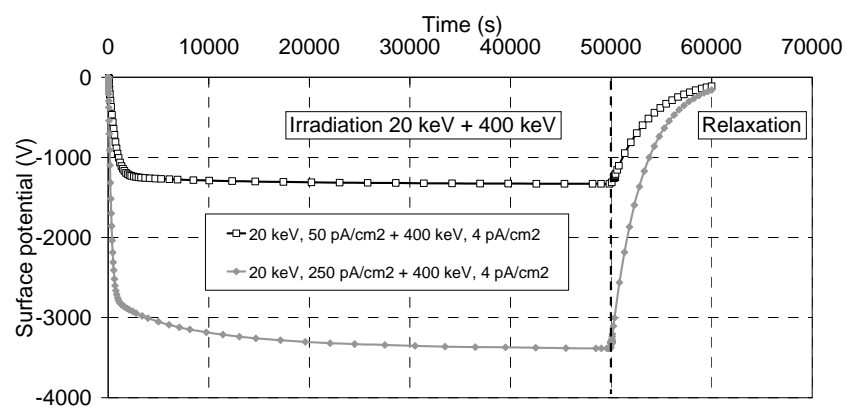

Fig. 19. Surface potential profiles assessed numerically for Kapton ${ }^{\circledR}$ under multi-energetic electron irradiation for two different charging $20 \mathrm{keV}$ fluexes

Fig. 19 presents the surface potential assessed numerically for Kapton ${ }^{\circledR}$ in GEO like irradiation conditions, taking into account the dependence of generation with the electric field. In this figure, we can notice that increasing the charging low energy current by a factor of 5 does not enhance the surface potential with the same factor (it rises only by a factor of 2) since RIC is enhanced with electric field, smoothing then the effect of charge flux increase. These numerical results are in good agreement with the experimental ones.

\section{CONCLUSION}

This paper demonstrates the complexity of conductive behaviour of polymers irradiated with high energy electrons. Radiation induced conductivity is indeed steered by several physical processes in competition and is therefore dependent upon radiation dose rate, total received radiation dose, electric field and temperature. Space polymer materials present very different charging behaviour depending on their physicochemical structure which acts on the mobilities, trapping properties, radical formation and lifetime of free charge carriers. A basic numerical model has been built and amended for a first insight of the physical processes that could rule radiation induced conductivity.

\section{ACKNOWLEDGMENT}

The authors would like to thank CNES, the French Space Agency, for fundings, technical and scientific support over the successive R\&T studies.

\section{REFERENCES}

[1] J.F. Fowler, "X-ray induced conductivity in insulating materials", Proceedings of the Royal Society of London. Series A, Mathematical and Physical Sciences, vol. 236, pp. 464-480, 1956.

[2] A. Rose, "Recombination processes in insulators and semiconductors", Phys.Rev., vol. 97, pp. 322-333, 1955.

[3] B. Gross, R.M. Faria, and G.F. Ferreira, "Radiation induced conductivity in Teflon irradiated by x rays," J.Appl.Phys., vol. 52, pp. 571-578, 1981.

[4] A.P. Tyutnev, V.S. Saenko, I.A. Smirnov and E.D. Pozhidaev, "Radiation induced conductivity in polymers during long term irradiation”, High.Ener.Chem., vol. 40, pp. 319-330, 2006

[5] T. Paulmier, B. Dirassen, D. Payan, M. Van Eesbeek, "Material Charging in Space Environment: Experimental Test Simulation and Induced Conductive Mechanisms", IEEE Trans. Dielectrics and Electrical Insulation, Vol. 16, pp 682-688, 2009.

[6] R. Hanna, T. Paulmier, P. Molinié, M. Belhaj, B. Dirassen, D. Payan, N. Balcon, "Radiation Induced Conductivity in Teflon FEP Irradiated With Multienergetic Electron Beam”, IEEE Trans. On Plasma Science, 41, 12, 2013, pp 3520-3525

[7] R. Hanna, T. Paulmier, P. Molinié, M. Belhaj, B. Dirassen, D. Payan, N Balcon, "Radiation induced conductivity in space dielectric materials", J. Appl. Phys., 115, 033713, 2014.A. Rose, "Recombination processes in insulators and semiconductors", Phys.Rev., vol. 97, pp. 322-333, 1955.

[8] P. Molinié, P. Dessante, R. Hanna, T. Paulmier, B. Dirassen, M. Belhaj, "Polyimide and FEP Charging Behavior under Multienergetic ElectronBeam Irradiation”, IEEE Trans. Dielectr. Electr. Insul., vol. 19, pp 12151220,2012

[9] W. Stark, R. Gerhard-Multhaupt, "Direct correlations between mechanical-relaxation measurements. Differential-scanning-calorimetry data, and thermally stimulated charge-decay results from Teflon-FEP electrets", Proceedings of 8th International Symposium on Electrets (ISE 8), Paris, France, Sept. 1994

[10] K.K. de Groh, M. Martin, "The effect of heating on the degradation of ground laboratory and space irradiated Teflon FEP", 6th International Conference on Protection of Materials and Structures from Space Environment, Toronto, Canada, May 2002

[11] L. Onsager, Initial Recombination of Ions, Phys. Rev., 54, 554, 1938

[12] R. H. Barlett, G. A. Fulk, R. S. Lee, and R. C. Weingart, "Temperature Dependence Of X,Ray_Induced Photoconductivity In Kapton And Teflon", IEEE Trans. Nucl. Sci., 22, 6, 1975

[13] P. M. Borsenberger, A. I. Ateya, "Predictions of the Onsager theory based on an exponential distribution of electron-hole separation distances", Journal Appl. Phys. 50, 909, 1979 


\section{Radiation Induced Conductivity Of Space Used Polymers Under High Energy Electron Irradiation}

ONERA : T Paulmier, B Dirassen, M. Arnaout CNES : D. Payan, N. Balcon 


\section{Overall Issue}

\section{Internal charging and Radiation induced effects}

- Harsh radiation environment in GEO, MEO, ...

- High fluxes at high energy levels : irradiation on inner elements

$\Rightarrow$ important effect on internal charging with potentially high charging kinetics

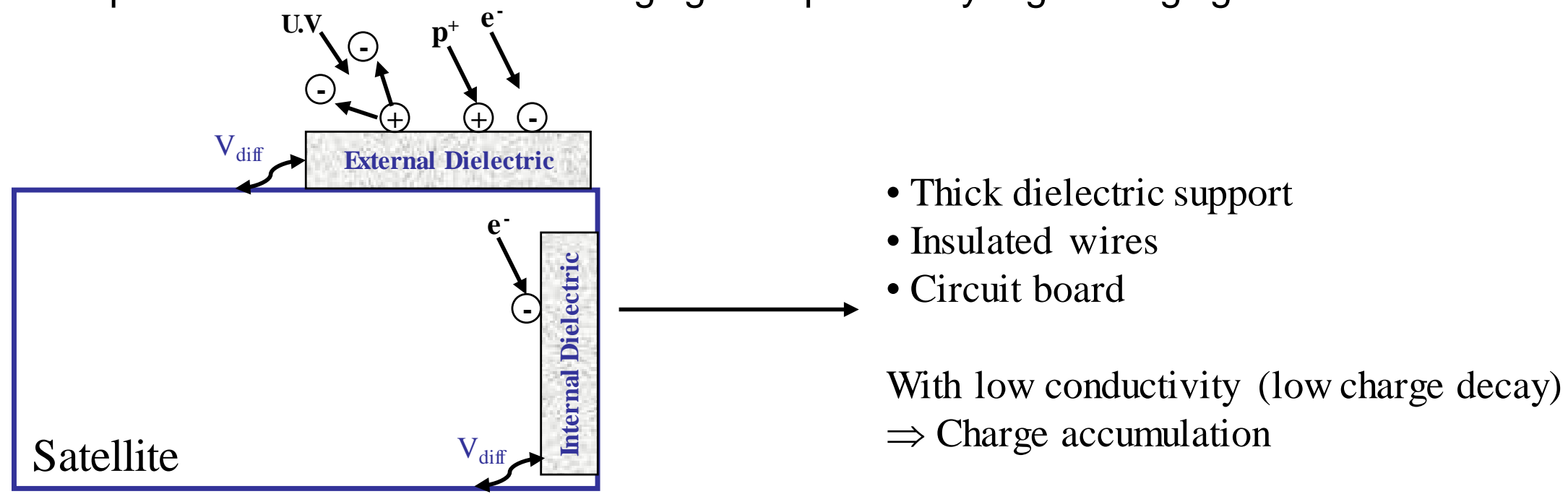

$-\Rightarrow$ Consequence : generation of high electric field

- Initiation of disruptive ESD

- Dielectric breakdown

- Damages on electronics

- Degradation of physical properties 


\section{Overall Issue}

\section{Physics steering internal charging}

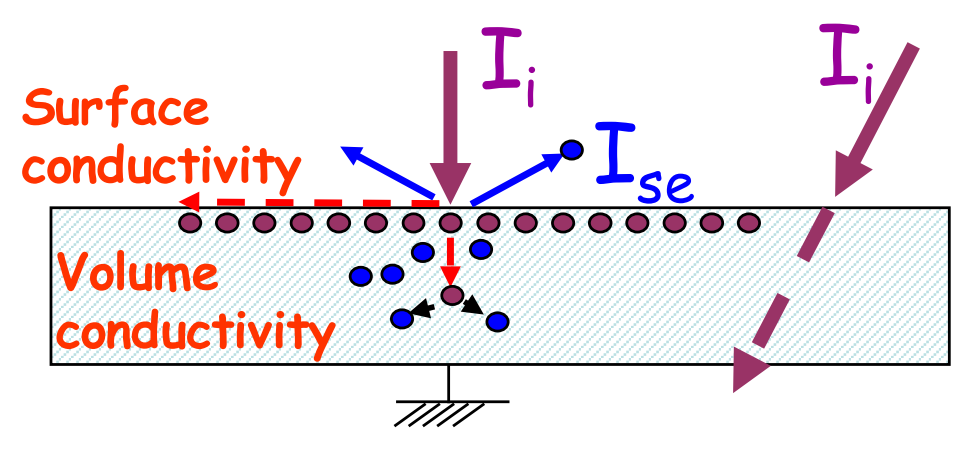

Effect on charging kinetics and decay - Bulk conductivity

- Surface conductivity

- Secondary electron emission

- Polarisation effect

- Radiation induced conductivity

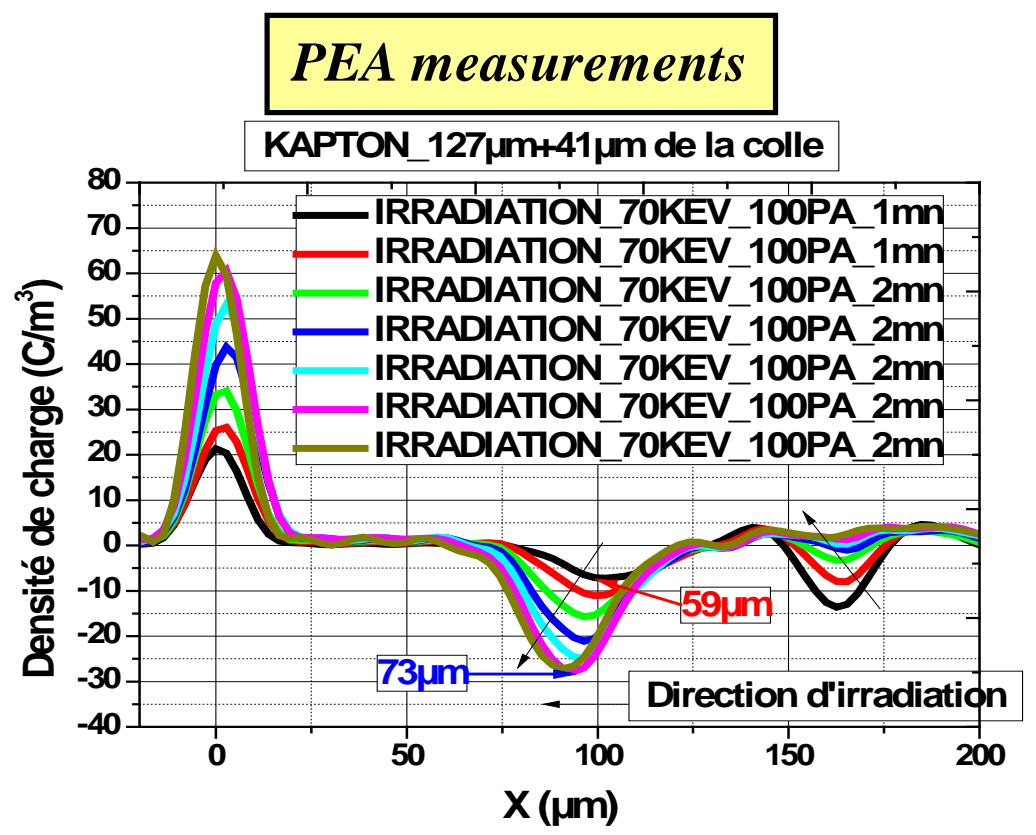




\section{Overall Issue Radiation Induced Effects - Simultaneous and delayed}

- Charging behaviour of materials in space

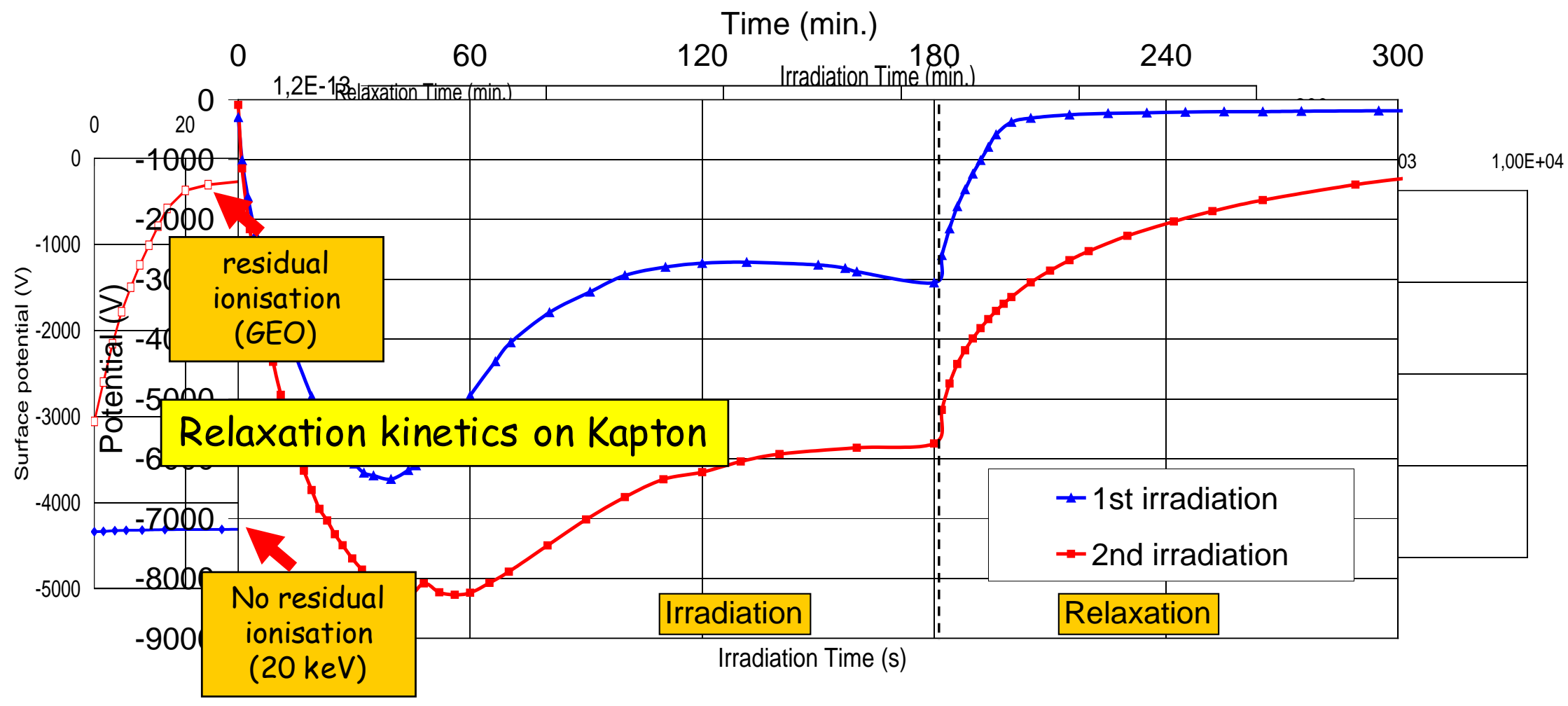

Effect of radiation dose

- Radiation induced conductivity - RIC (instantaneous effect)

$$
\sigma_{\text {ric }}=k\left(\frac{d D}{d t}\right)^{\Delta}
$$

- Effect of radiation dose $: \sigma_{R I C}=f(D)$

- Temporary effect : Delayed RIC See Poster\#151

- Permanent effect : Physical and chemical ageing 


\section{Objectives and overall approach}

\section{Objective of this study}

- Understanding the physical mechanisms steering radiation induced conductivity

- Improve and amend the physics models describing charging kinetics of spaced used materials

\section{Approach}

- Experimental Characterisation of charge transport and physical effect on RIC

- Parametric study : Effect of electric field, temperature, charge carrier (electrons vs holes)

- Analysis through different characterisation tools (KP, PEA ,...)

- Numerical codes for implementation of all physics effect 


\section{SIRENE facility}

\section{SIRENE functions}

- Charging of space materials under representatiive electron beam spectrum in energy range [0-400 keV]

- Assessment of intrinsic and radiation induced conductivities (bulk and surface)

- Ageing through electron radiation (400 keV)

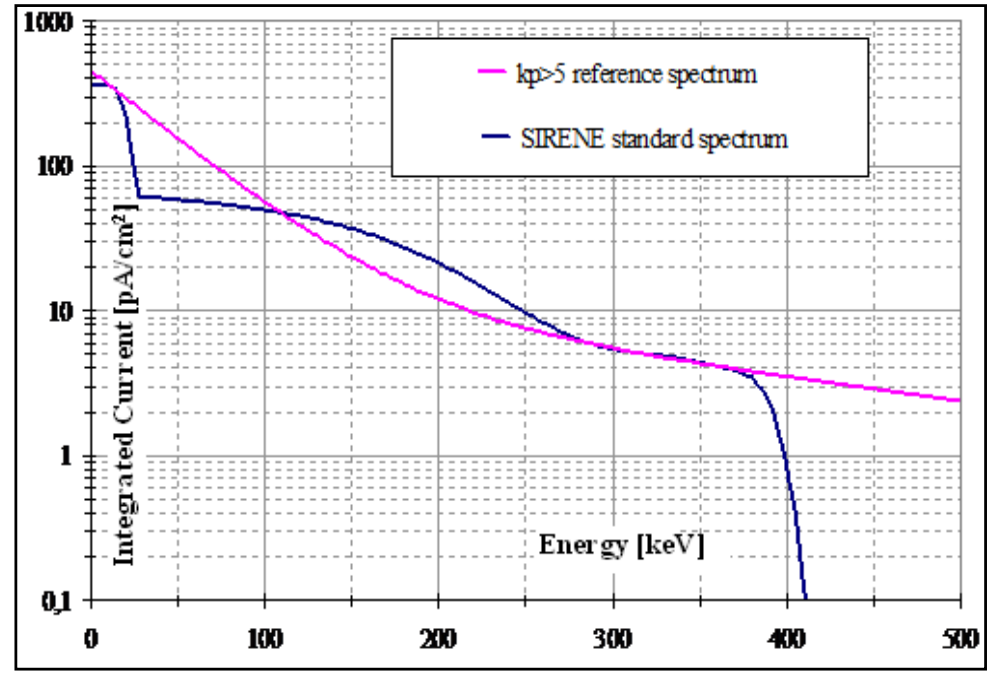

$\mathrm{Kp}$ is a common index used to indicate the severity of the global magnetic disturbances in near-Earth space

SIRENE spectrum, standard flux :

$\mathrm{E}=20 \mathrm{keV}, \mathrm{F}=250 \mathrm{pA} / \mathrm{cm}^{2}+\mathrm{E}=0-400 \mathrm{keV}, \mathrm{F}=50 \mathrm{pA} / \mathrm{cm}^{2}$

\section{SIRENE Facility Characteristics :}

$\checkmark$ Two monoenergetic electron beams:

Electron gun : energy of 7 to $100 \mathrm{keV}$, fluxes $0-5 \mathrm{nA} / \mathrm{cm} 2$

Van de Graaff accelerator: $400 \mathrm{keV}, 1$ pA. $\mathrm{cm}^{-2}-5$ nA. $\mathrm{cm}^{-2}$

$\checkmark \underline{\text { Instrumentation: Kelvin probe, PEAin situ, current }}$

$\checkmark$ Operating conditions :

Vaccum : $10^{-6}$ torr

Temperature : $-150^{\circ} \mathrm{C} /+250^{\circ} \mathrm{C}$

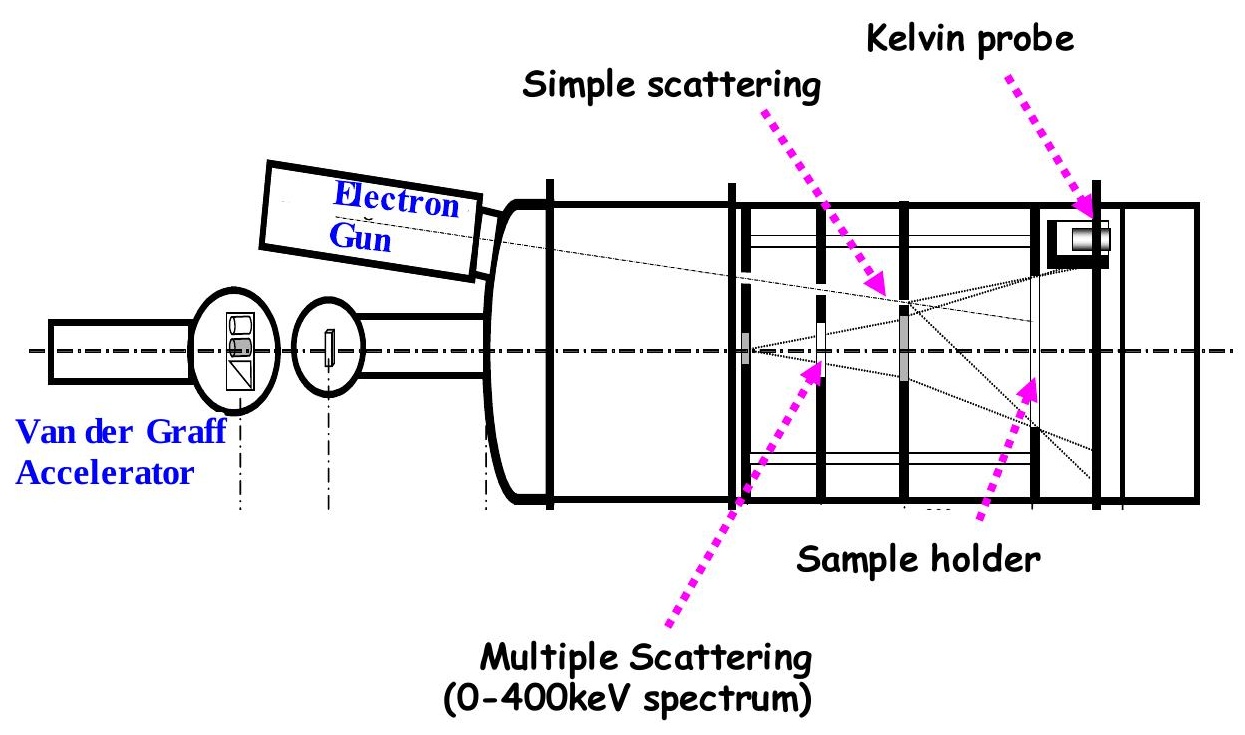




\section{SIRENE facility}
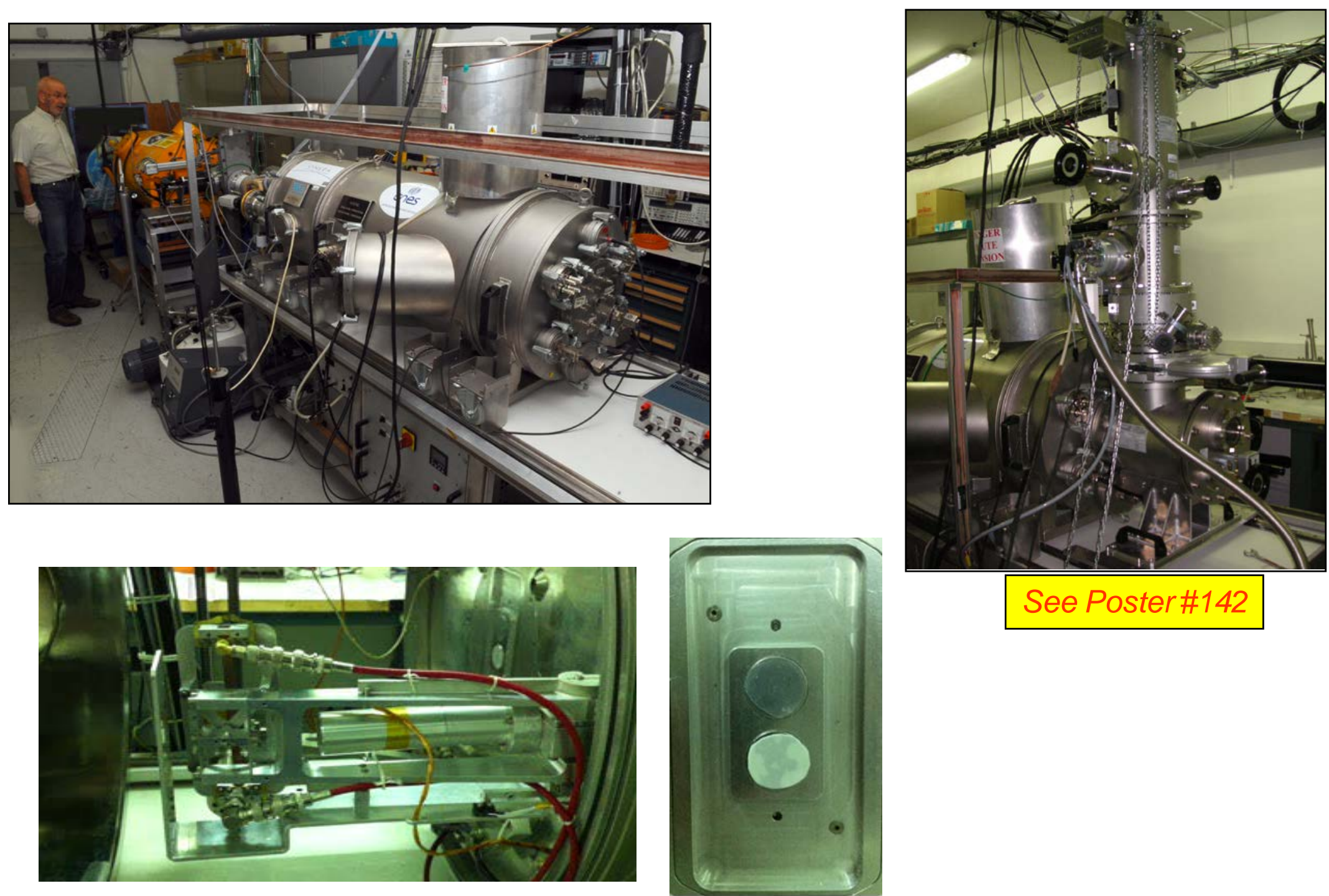


\section{Experimental Results}

\section{Why?}

\section{Electric field effect on RIC and DRIC}

\section{Evaluation of RIC through relaxation enhanced with $400 \mathrm{keV}$ electron beam (with controlled dose rate)}

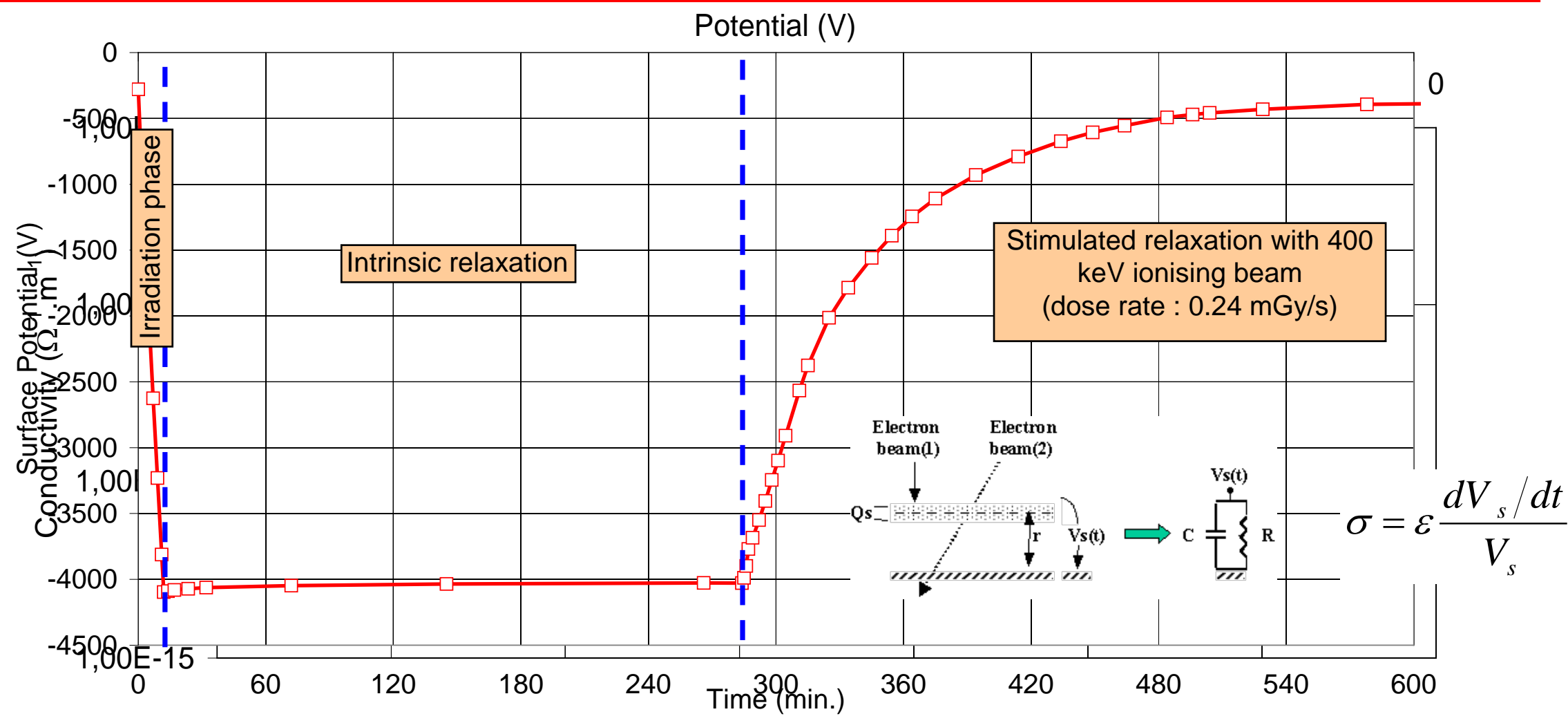

- Decrease of RIC with electric field ?

- Does this steep electric field drop competes with ionisation?

- Which mechanism steers this electric field effect on RIC ? 


\section{Experimental Results}

\section{Electric field effect on RIC, photo-conduction and DRIC}

\section{Evaluation of RIC through potential relaxation :}

1. Charge with $20 \mathrm{keV}$ at different given surface potentials

2. Stimulation of potential relaxation with $400 \mathrm{keV}$ electron beam or light

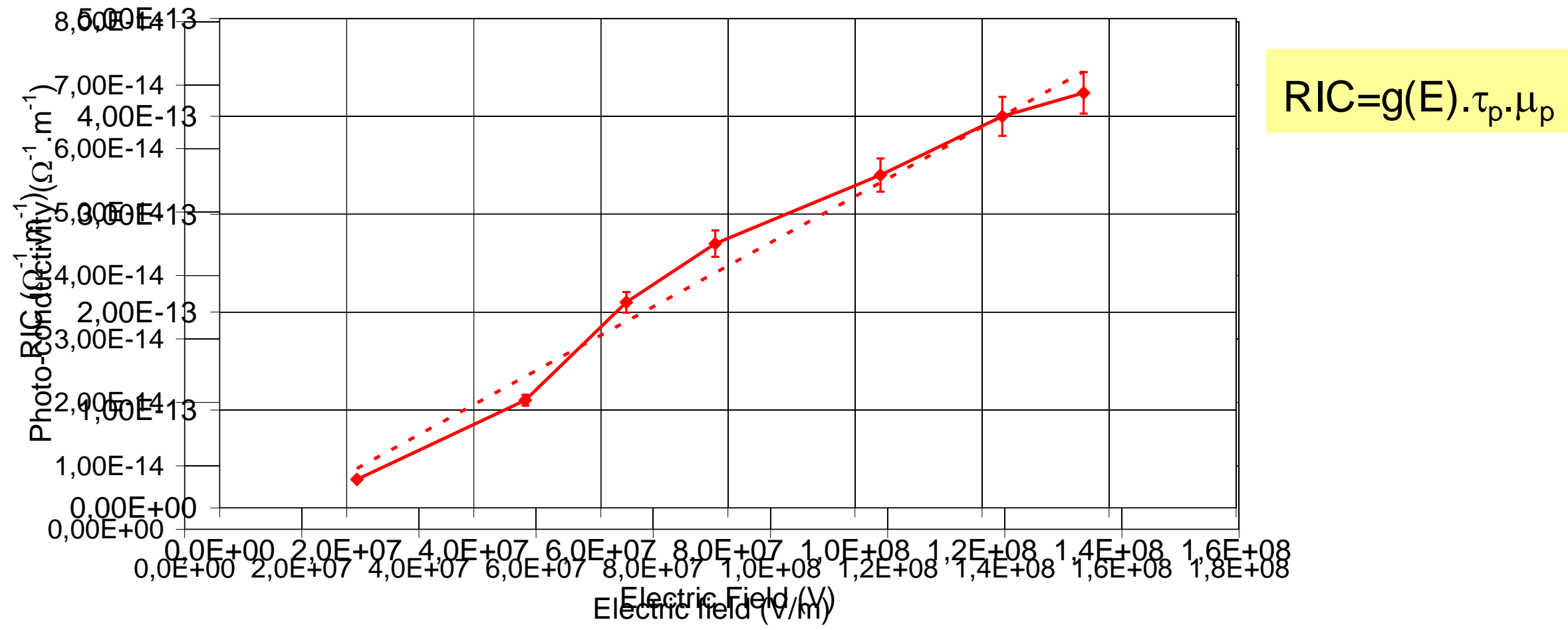




\section{Experimental Resulits}

\section{Electric field effect on RIC, photo-conduction and DRIC}

- Linear evolution of RIC with electric field

- DRIC is not electric field dependent

$\Rightarrow$ Field effect not due to E-induced detrapping or electro de injection

$\Rightarrow$ Effect on electron -hole pairs generation through "geminate recombination" (Onsager theory)

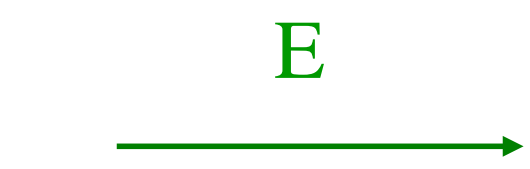

Electrons

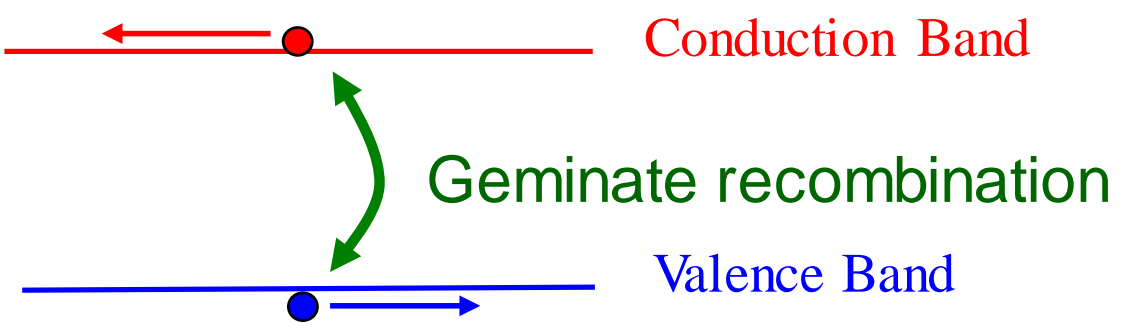

Holes
$\Rightarrow$ Recombination rises when $\mathrm{E}$ decreases

$\Rightarrow$ Increase of effective generation rate with $\mathrm{E}$

$$
G(E, T) \propto \exp \left(-e^{2} / \varepsilon \cdot k \cdot T \cdot r_{0}\right) \cdot\left(1+e^{3} \cdot E / 8 \cdot \pi \cdot \varepsilon \cdot k^{2} \cdot T^{2}\right)
$$

$\Rightarrow$ Electric field effect much less conspicuous on fluorine materials (Teflon FEP) or PEEK

Good qualitative and
quantitative fit with the
Onsager theory




\section{Experimental Results Temperature effect}

\section{Does RIC depend on temperature ?}

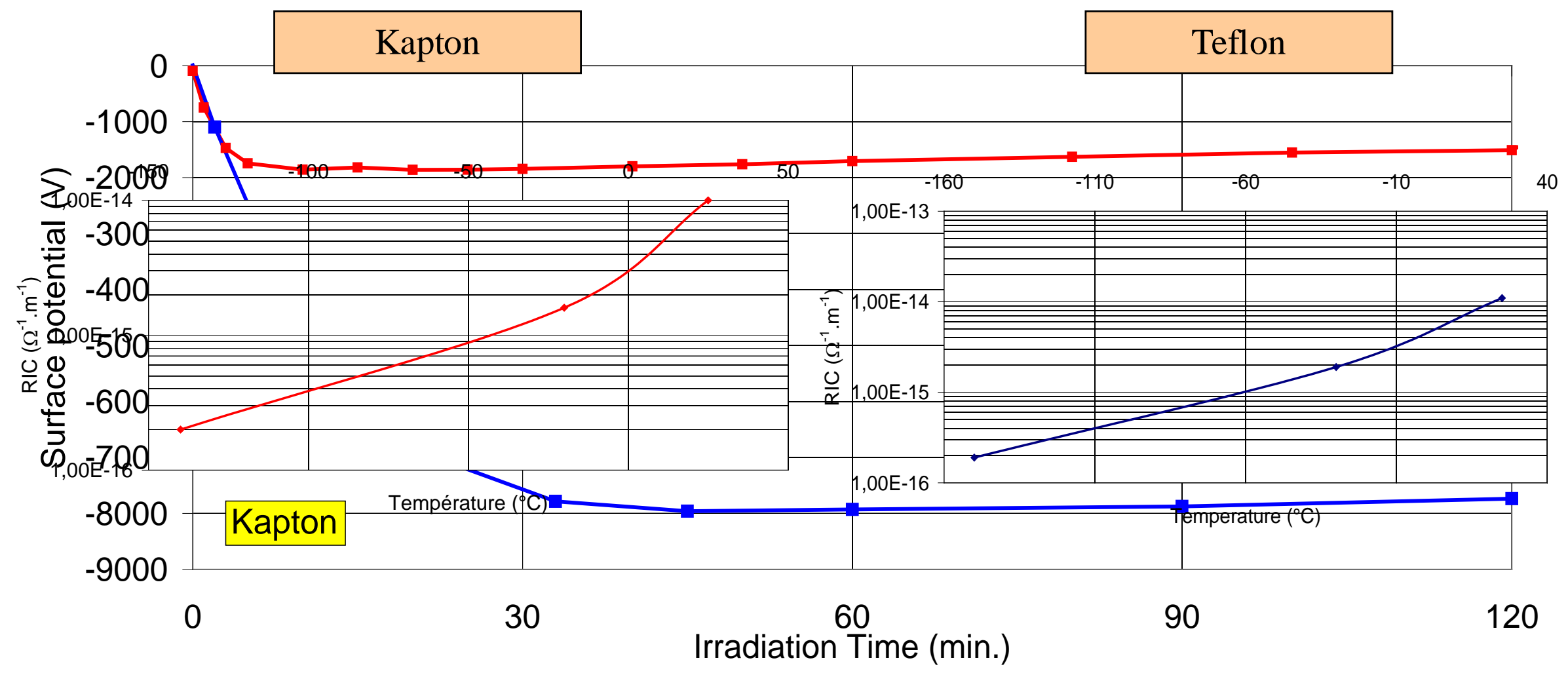




\section{Experimental Results Temperature effect}

- No possible simple experimental fit

- DRIC is temperature dependent

- Combination of different temperature activated physical processes

$\Rightarrow$ generation rate

$$
G(E, T) \propto \exp \left(-e^{2} / \varepsilon \cdot k \cdot T \cdot r_{0}\right) \cdot\left(1+e^{3} \cdot E / 8 \cdot \pi \cdot \varepsilon \cdot k^{2} \cdot T^{2}\right)
$$

$\Rightarrow$ Charge Detrapping

$$
\tau_{n}=\tau_{0} \cdot \exp \left(\frac{E_{a}}{k . T}\right)
$$

$\Rightarrow$ Charge carrier mobility

$$
\mu=\mu(E, T)
$$

$\Rightarrow$ Molecular mobility

$\Rightarrow$ Hopping processes

$$
\begin{gathered}
\sigma=\sigma_{0} \cdot\left(T_{0} / T\right)^{1 / 4} \cdot \beta_{1}(E) \cdot \exp \left[-\beta_{2} \cdot\left(T_{0} / T\right)^{1 / 4}\right] \\
\text { See Poster } \# 141
\end{gathered}
$$




\section{Experimental Resulits}

\section{Specific behaviour of fluorine polymer materials}

\section{Fluorine materials}

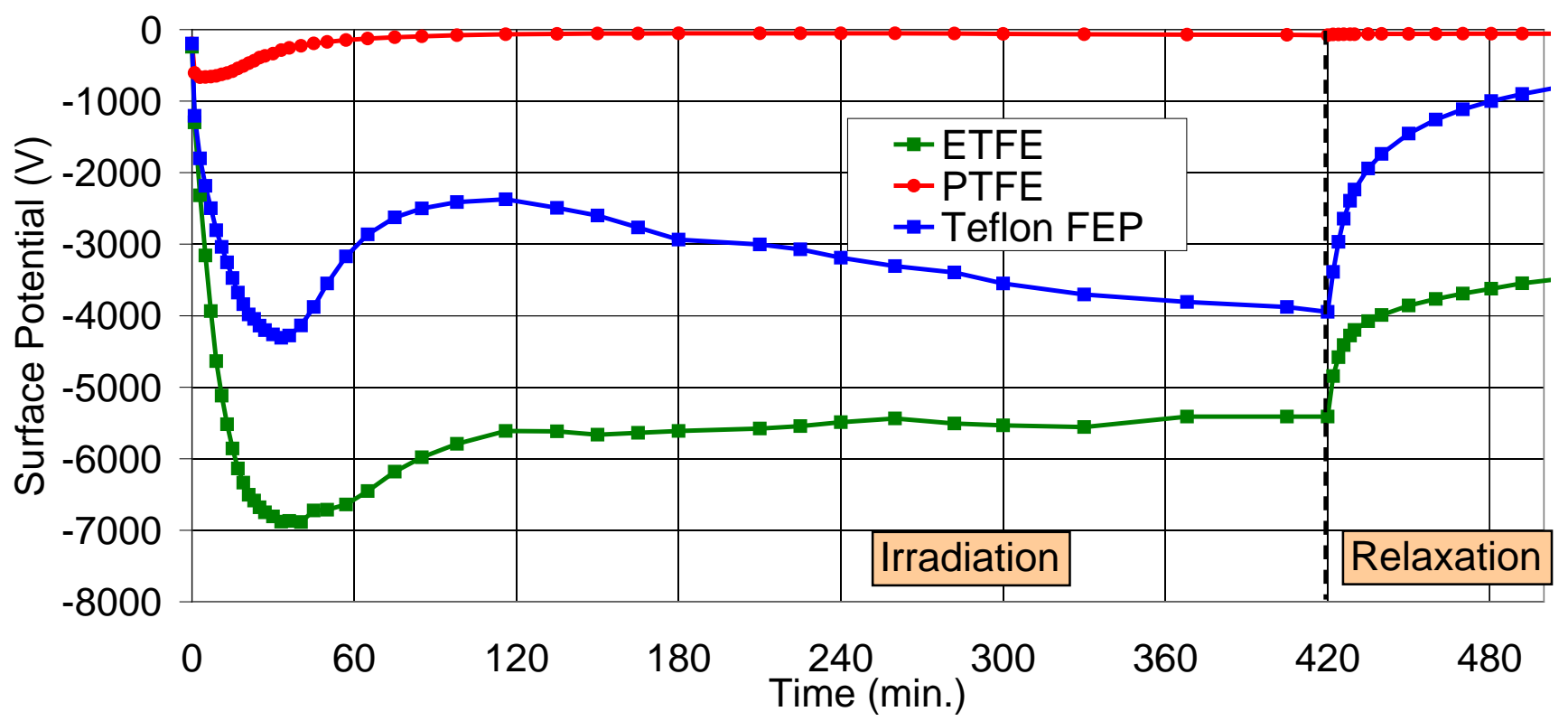

FEP

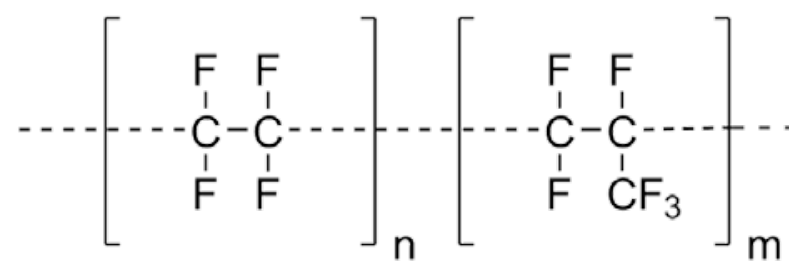

PTFE

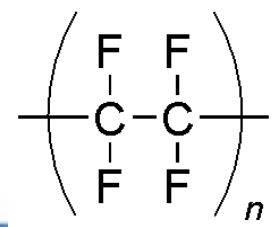

Potential physical explanation :

- Cristallinity ratio differences (act on trap distribution

- Different molecular mobility

- Effect of radicals on charge trapping 


\section{Discussion}

\section{Physics and numerical models for RIC description}

\section{Circuit model}

Two traps model

$$
\left(\begin{array}{l}
\frac{d n}{d t}=g(E)-\alpha_{1} n\left(p_{t 1}+p_{t 2}\right)-\frac{n}{\tau_{n}}-\frac{n}{\tau_{n 2}}+\frac{n_{t 1}}{\tau_{n t 1}}+\frac{n_{t 2}}{\tau_{n t 2}} \\
\frac{d n_{t 1}}{d t}=\frac{n}{\tau_{n}}+\frac{n}{\tau_{n 2}}-\frac{n_{t 1}}{\tau_{n t 1}}-\alpha_{2} p n_{t 1} \\
\frac{d n_{t 2}}{d t}=\frac{n}{\tau_{n}}+\frac{n}{\tau_{n 2}}-\frac{n_{t 2}}{\tau_{n t 2}}-\alpha_{2} p n_{t 2} \\
\frac{d p}{d t}=g(E)-\alpha_{2}\left(n_{t 1}+n_{t 2}\right) p-\frac{p}{\tau_{p}}-\frac{p}{\tau_{p 2}}+\frac{p_{t 1}}{\tau_{p t 1}}+\frac{p_{t 2}}{\tau_{p t 2}} \\
\frac{d p_{t 1}}{d t}=\frac{p}{\tau_{p}}+\frac{p}{\tau_{p 2}}-\frac{p_{t 1}}{\tau_{p t 1}}-\alpha_{1} n p_{t 1} \\
\frac{d p_{t 2}}{d t}=\frac{p}{\tau_{p}}+\frac{p}{\tau_{p 2}}-\frac{p_{t 2}}{\tau_{p t 2}}-\alpha_{1} n p_{t 2}
\end{array}\right)
$$

$\mathrm{I}_{\mathrm{i}}=\mathrm{I}_{\mathrm{Q}}+\mathrm{I}_{\mathrm{SE}}+\mathrm{I}_{\text {surf }}+\mathrm{I}_{\mathrm{R}}$

$\mathrm{I}_{\mathrm{Q}}+\mathrm{I}_{\mathrm{R}}=\mathrm{I}_{\mathrm{i} \cdot} \cdot(1-\eta-\beta)$

C. $d V / d t+V / R=I_{i} \cdot(1-\eta-\beta)$

$\mathrm{dV} / \mathrm{dt}=(\mathrm{Ji} . \mathrm{L} .(1-\eta-\beta)-\sigma \cdot \mathrm{V}) / \varepsilon$

$\sigma=e .\left(n_{-} \cdot \mu_{-}+n_{+} \cdot \mu_{+}\right)$
Electrons

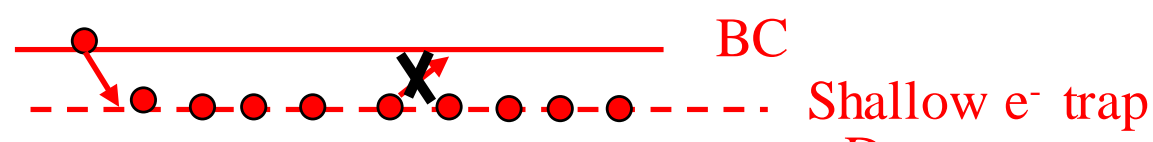

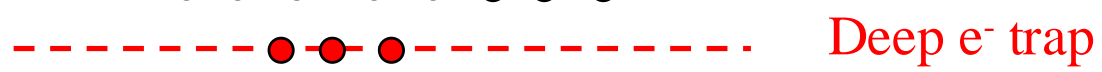

Deep hole trap

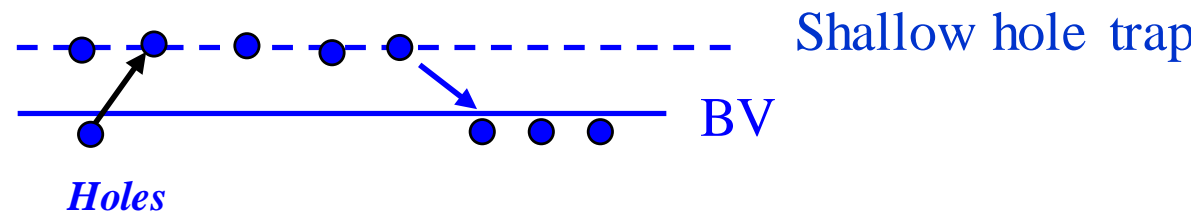




\section{Discussion}

\section{Physics and numerical models for RIC description}

\section{Circuit model}

\section{Cu Electric field effect effect}

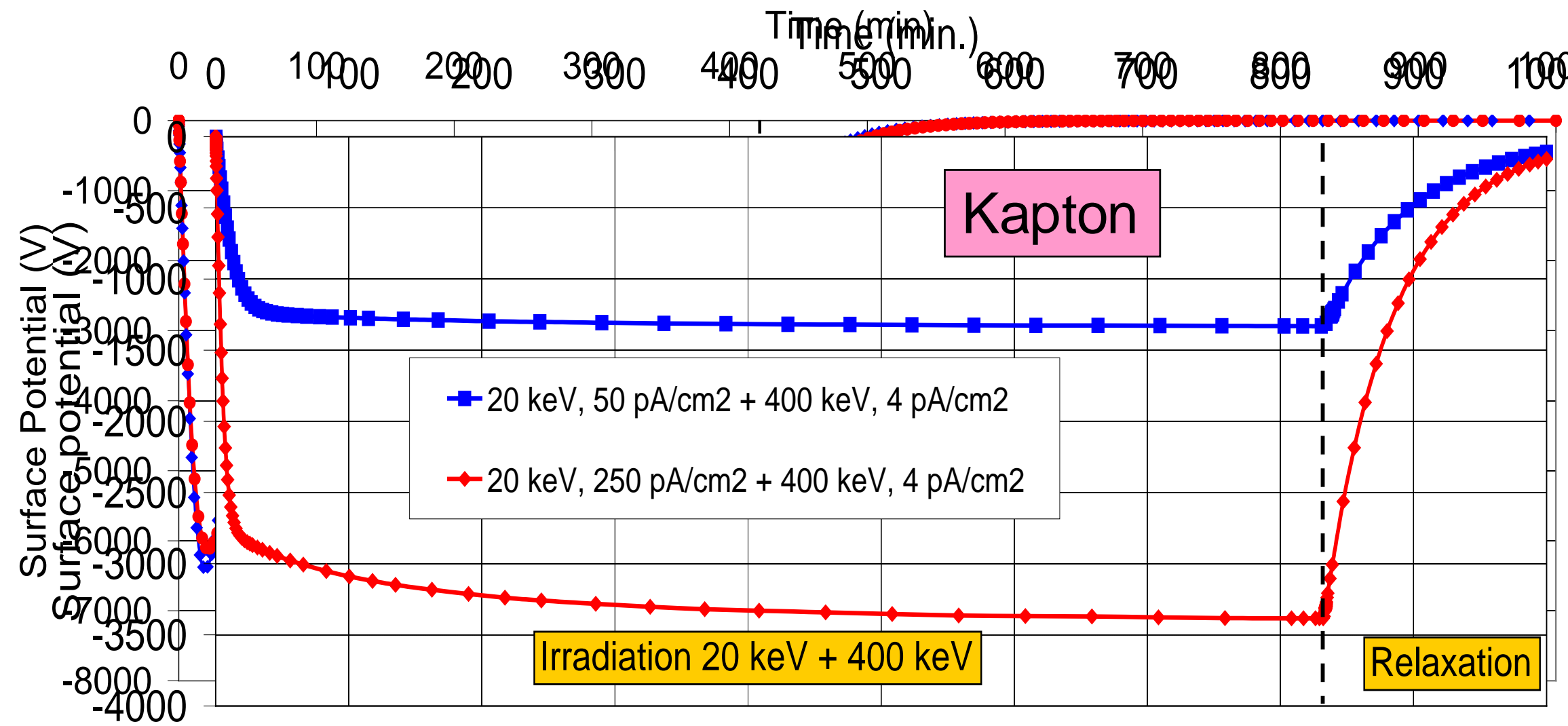

$\Rightarrow$ Dependency of generation rate on electric field

$\Rightarrow$ Stability of trapped electrons

$\Rightarrow$ Steady increase of free holes density through constent detrapping

$\Rightarrow$ Significant rise of RIC 
- Internal charging can be highly steered by radiation conductivity induced by high energy electrons coming through the inner parts of spacecraft

- Requirement for charging prediction and RIC analysis

- RIC depends on various parameters :

- Radiation dose and dose rate

- Electric field

- Temperature

- Material structure and state (composition, structure, cristallinity, ...)

- Radical formation and generation rate (?)

- RIC steered by complex physical mechanisms

- Development of physics model and numerical codes for charge prediction and physical analysis 


\section{Outlooks}

- Several experimental and numerical studies in progress on internal charging issues at ONERA $\Rightarrow$ topic getting greater concerns

-1D Model

- Radiation Induced Conductivity studies :

- Optimisation of Circuit and 1D model

- Better correlation between structure / RIC of polymer materials + effect of radicals on RIC

- Implementation of the first model in spacecraft charging prediction codes (SPIS) 


\section{Thankyou foryourattention}

